\title{
ACE-2 HILLCLOUD. An overview of the ACE-2 ground-based cloud experiment
}

By K. N. BOWER ${ }^{1 *}$, T. W. CHOULARTON ${ }^{1}$, M. W. GALlAGHER ${ }^{1}$, K. M. BESWICK ${ }^{1}$, M. J. FLYNN ${ }^{1}$, A. G. ALLEN ${ }^{2}$, B. M. DAVISON ${ }^{10}$, J. D. JAMES ${ }^{2}$, L. ROBERTSON ${ }^{10}$, R. M. HARRISON $^{2}$, C. N. HEWITT ${ }^{10}$, J. N. CAPE ${ }^{3}$, G. G. McFADYEN ${ }^{3}$, C. MILFORD ${ }^{3}$, M. A. SUTTON ${ }^{3}$, B. G. MARTINSSON ${ }^{4}$, G. FRANK ${ }^{4}$, E. SWIETLICKI ${ }^{4}$, J. ZHOU ${ }^{4}$, O. H. BERG ${ }^{4}$, B. MENTES ${ }^{4}$, G. PAPASPIROPOULOS ${ }^{4}$, H.-C. HANSSON ${ }^{5}$, C. LECK $^{5}$, M. KULMALA ${ }^{6}$, P. AALTO ${ }^{6}$, M. VÄKEVÄ ${ }^{6}$, A. BERNER ${ }^{7}$, M. BIZJAK ${ }^{13}$, S. FUZZI ${ }^{8}$, P. LAJ ${ }^{8}$, M.-C. FACCHINI ${ }^{8}$, G. ORSI ${ }^{8}$, L. RICCI ${ }^{8}$, M. NIELSEN ${ }^{9}$, B. J. ALLAN ${ }^{11}, \mathrm{H} \cdot \mathrm{COE}^{11}$, G. McFIGGANS ${ }^{11}$, J. M. C. PLANE ${ }^{11}$; J. L. COLLETT Jr. ${ }^{12}$, K. F. MOORE ${ }^{12}$ and D. E. SHERMAN ${ }^{12}$

${ }^{1}$ The Physics Department, University of Manchester Institute of Science and Technology, PO Box 88, Manchester, M60 1QD, UK; ${ }^{2}$ Institute of Public and Environmental Health, University of Birmingham, Edgbaston, Birmingham, B15 2TT, UK; ${ }^{3}$ Institute of Terrestrial Ecology, NERC, Edinburgh Research Station, Bush Estate, Pencuik EH26 OQB, UK; ${ }^{4}$ Division of Nuclear Physics, Lund University, PO Box 118, S-22100 LUND, Sweden; ${ }^{5}$ Air Pollution Laboratory, Institute of Applied Environmental Research, Stockholm University, Sweden; ${ }^{6}$ The Physics Department, University of Helsinki, PO Box 9 FIN-00014, Helsinki, Finland; ${ }^{7}$ Institut fur Experimentalphysik, Universitat Wien, Strudlhofgasse 4, A-1090, Wien, Austria; ${ }^{8}$ Istituto FISBAT (now ISAO: Institute of Atmospheric and Oceanic Sciences), CNR (Consilio Nazionale delle Ricerche), Via Gobetti 101, 40129 Bologna, Italy; ${ }^{9}$ RISØ National Laboratory, Roskilde, Denmark; ${ }^{10}$ Institute of Environmental and Natural Sciences, University of Lancaster, Lancaster, LA1 4YQ, UK. ${ }^{11}$ School of Environmental Sciences, University of East Anglia, Norwich, NR4 7TJ, UK; ${ }^{12}$ Atmospheric Science Department, Colorado State University, Fort Collins, Colorado 80523 USA;

${ }^{13}$ National Institute of Chemistry, Hajdrihova 19, 61115, Ljubljana, Slovenia

(Manuscript received 2 February 1999; in final form 29 October 1999)

\section{ABSTRACT}

The ACE-2 HILLCLOUD experiment was carried out on the island of Tenerife in June-July 1997 to investigate the interaction of the boundary layer aerosol with a hill cap cloud forming over a ridge to the north-east of the island. The cloud was used as a natural flow through reactor to investigate the dependence of the cloud microphysics and chemistry on the characteristics of the aerosols and trace gases entering cloud, and to simultaneously study the influence of the physical and chemical processes occurring within the cloud on the size distribution, chemical and hygroscopic properties of the aerosol exiting cloud. 5 major ground base sites were used, measuring trace gases and aerosols upwind and downwind of the cloud, and cloud microphysics and chemistry and interstitial aerosol and gases within the cloud on the hill. 8 intensive measurement periods or runs were undertaken during cloud events, (nocturnally for seven of the eight runs) and were carried out in a wide range of airmass conditions from clean maritime to polluted continental. Polluted air was characterised by higher than average concentrations of ozone ( $>50 \mathrm{ppbv})$, fine and accumulation mode aerosols $\left(>3000\right.$ and $>1500 \mathrm{~cm}^{-3}$, respectively) and higher aerosol mass loadings. Cloud droplet number concentrations $N$,

\footnotetext{
* Corresponding author.
}

email: k.bower@umist.ac.uk 
increased from $50 \mathrm{~cm}^{-3}$ in background maritime air to $>2500 \mathrm{~cm}^{-3}$ in aged polluted continental air, a concentration much higher than had previously been detected. Surprisingly, $N$ was seen to vary almost linearly with aerosol number across this range. The droplet aerosol analyser (DAA) measured higher droplet numbers than the corrected forward scattering spectrometer probe (FSSP) in the most polluted air, but at other times there was good agreement (FSSP $=$ 0.95 DAA with an $r^{2}=0.89$ for $N<1200 \mathrm{~cm}^{-3}$ ). Background ammonia gas concentrations were around $0.3 \mathrm{ppbv}$ even in air originating over the ocean, another unexpected but important result for the region. $\mathrm{NO}_{2}$ was present in background concentrations of typically 15 pptv to 100 pptv and $\mathrm{NO}_{3}$ (the nitrate radical) was observed at night throughout. Calculations suggest $\mathrm{NO}_{3}$ losses were mainly by reaction with DMS to produce nitric acid. Low concentrations of $\mathrm{SO}_{2}$ ( $\sim 30$ pptv), $\mathrm{HNO}_{3}$ and $\mathrm{HCl}$ were always present. $\mathrm{HNO}_{3}$ concentrations were higher in polluted episodes and calculations implied that these exceeded those which could be accounted for by $\mathrm{NO}_{2}$ oxidation. It is presumed that nitric and hydrochloric acids were present as a result of outgassing from aerosol, the $\mathrm{HNO}_{3}$ from nitrate rich aerosol transported into the region from upwind of Tenerife, and $\mathrm{HCl}$ from sea salt aerosol newly formed at the sea surface. The oxidants hydrogen peroxide and ozone were abundant (i.e., were well in excess over $\mathrm{SO}_{2}$ throughout the experiment). Occasions of significant aerosol growth following cloud processing were observed, particularly in cleaner cases. Observations and modelling suggested this was due mainly to the take up of nitric acid, hydrochloric acid and ammonia by the smallest activated aerosol particles. On a few occasions a small contribution was made by the in-cloud oxidation of S(IV). The implications of these results from HILLCLOUD for the climatologically more important stratocumulus Marine Boundary Layer (MBL) clouds are considered.

\section{Introduction}

Aerosol particles play an important rôle in the radiation budget of the earth's atmosphere. They have a direct effect by absorbing and scattering incoming solar radiation, but they also have an indirect effect via the rôle they play as cloud condensation nuclei $(\mathrm{CCN})$, the aerosol particles upon which cloud droplets activate. Along with cloud dynamics, the CCN population controls the number and size of cloud droplets which form and so affects the radiative properties of clouds. Additionally, these parameters regulate precipitation development and hence cloud lifetime and so aerosols exert a further influence on cloud radiative properties in this way. The uncertainties in the direct and indirect radiative properties of aerosols are still considerably larger than those of any other contribution to the total radiative forcing of the earths atmosphere, the contribution of the indirect effect being the least certain of all (ICCP, 1996). It is clear, therefore, that processes controlling or changing the properties of aerosol should be carefully investigated. This will improve our understanding of how aerosols and clouds may modify the future climate changes expected to result from continued increases in greenhouse gas emissions and through other anthropogenic activities.
ACE-2 or "The North Atlantic Regional Aerosol Characterisation Experiment" is the 3rd experiment in a series (coordinated by IGAC, the International Global Atmospheric Chemistry Project) that addresses the properties of the atmospheric aerosol relevant to radiative forcing and climate. An overview of the aims of ACE-2 is given in Raes et al. (2000), along with a general description of the integrated ACE-2 field projects performed, in the anthropogenically modified atmosphere of the sub-tropical North Eastern Atlantic region (from the ocean west and south of the Iberian peninsular to the Canary Islands and east to the African coast) during June and July of 1997. One of these projects was "HILLCLOUD" a study of the processing of an aerosol population following a single passage through a Marine Boundary Layer (MBL) cloud. This activity, a new element in the ACE series of experiments, made use of the hill cap cloud which forms over the Anaga ridge to the NE of the island of Tenerife (Fig. 1) as a natural flow through reactor to investigate the general ACE-2 objectives (Raes et al., 2000) and in particular:

(1) the relationship between the cloud droplet size distribution and the chemical composition, size distribution and hygroscopic properties of the aerosol entering the cloud; 


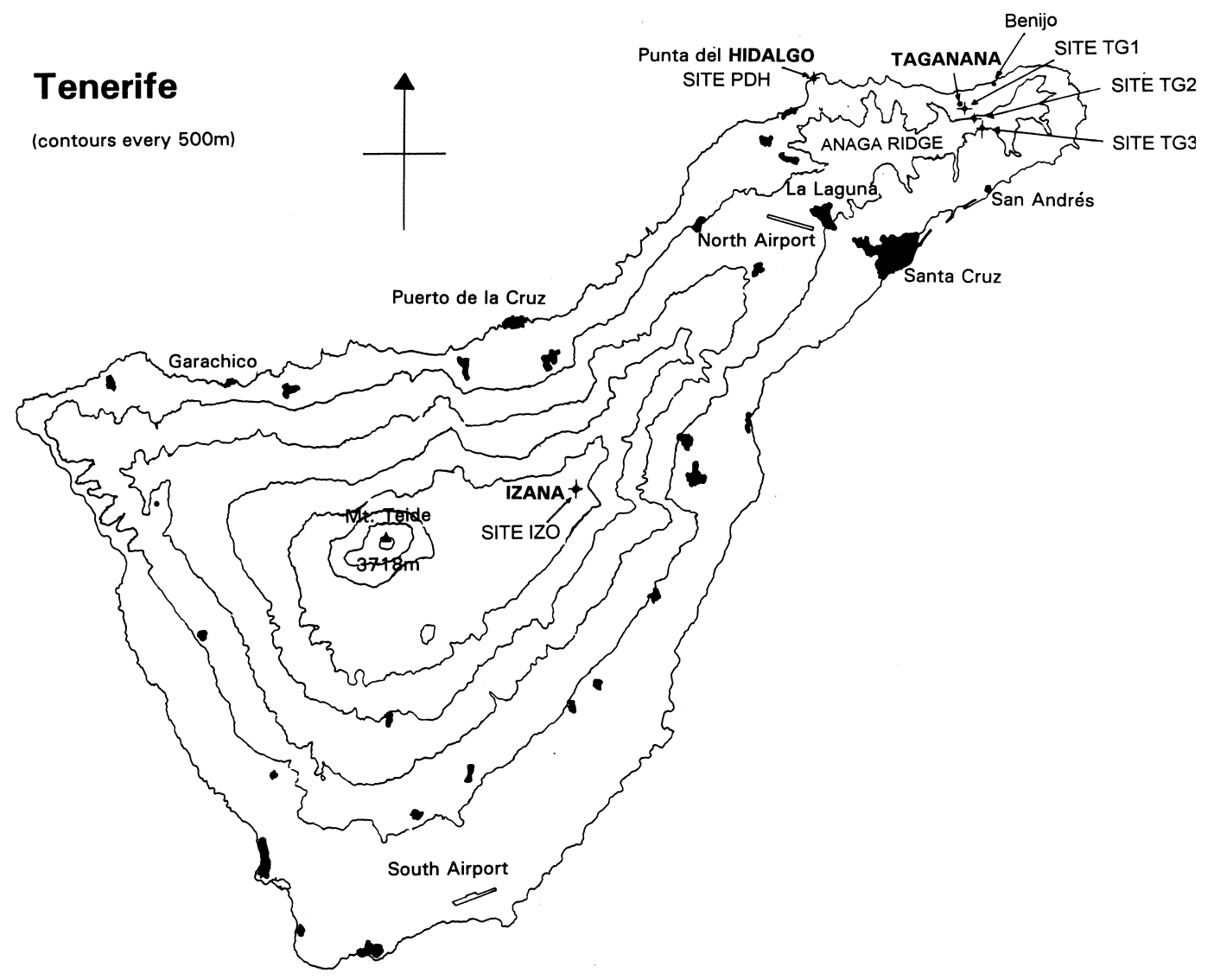

Fig. 1. Map of Tenerife. The "HILLCLOUD" experiment was carried out over the Anaga ridge to the NE of the island (contours every $500 \mathrm{~m}$ ).

(2) the nucleation scavenging of aerosol as it enters cloud base as a function of particle size and chemistry;

(3) the effect of aqueous phase cloud chemistry, including the oxidation of S(IV), the production of nitrate ions, the solution of soluble trace gases on the size distribution, chemical composition and hygroscopic properties of the aerosol;

(4) possible processes producing new ultra-fine particles by gas to particle conversion near cloud;

(5) the effects of the entrainment of free tropospheric air through cloud top on each of the above.

An additional aim of HILLCLOUD (in conjunction with the "FREEROPE" ACE-2 project Raes et al., 2000) was to characterise the size distribution, size dependent chemical composition and hygroscopic properties of the marine and modified continental aerosol arriving at the North coast of Tenerife, together with the concomitant trace gas concentrations at the same sites.

In this paper, we do not aim to present a comprehensive review of all the results obtained in all the different conditions throughout the whole experiment. Such an overview can only be written at some time in the future when all data have been analysed in detail and specialist papers written. At this early stage of the analysis, the goal of this overview paper is thus:

(1) to provide background information to the reader about the objectives and aims of the HILLCLOUD experiment;

(2) to describe the operational set-up and methodology;

(3) to include material which is of use to the other specialised HILLCLOUD papers in this issue, but which would be tedious to read over 
and over again in each of these papers (e.g., equipment lists ...):

(4) to summarise the general conditions and results of each of the HILLCLOUD runs;

(5) to highlight the main results and to indicate which were new and/or unexpected;

(6) to briefly discuss the implications of these main results for the indirect radiative forcing in the region of the eastern North Atlantic investigated.

\section{Scientific description of the HILLCLOUD project}

\subsection{Concept of the hill cap cloud experiment}

In the ACE-2 HILLCLOUD experiment, the idea was to use the hill-cap-cloud which forms over the Anaga ridge (Fig. 1) to the north-east of the island of Tenerife as a natural flow through reactor to investigate the dependence of the cloud microphysics and chemistry on the characteristics of the aerosols and trace gases entering cloud, and to simultaneously study the influence of the physical and chemical processes occurring within the cloud on the size distribution, chemical and hygroscopic properties of the aerosol exiting cloud. To achieve these goals, HILLCLOUD employed 3 major ground based sites and shared two others with the FREETROPE experiment during the main ACE-2 campaign of 1997. These sites were chosen prior to the ACE-2 pre-campaign of June-July 1996 during which they were partially characterised and also had their appropriateness assessed for use during the main experiment of 1997.

Previous experiments (Bower et al., 1999; Choularton et al., 1997) have confirmed the viability of the cloud flow through experiment concept. In these hillcloud experiments, the cloud forms as moisture laden air approaching the hill is forced to rise and cool as it crosses over the elevated regions. Initially this cooling leads to an increase in the relative humidity of the air and causes aerosol within it to swell through condensation. If the ascent continues a supersaturation develops, and the largest aerosol acting as $\mathrm{CCN}$ experience explosive growth as they become activated into cloud drops. Further ascent leads to efficient growth of these drops. This causes a reduction in the supersaturation and (for a hill of simple shape in which there are no subsequent larger peaks in supersaturation) prevents the activation of the smaller aerosol (which require larger supersaturations to activate them than the larger aerosols). These aerosol remain interstitial to the cloud drops during passage over the hill. Downwind of the ridge the air warms during descent and becomes undersaturated. Droplets start to evaporate and eventually the cloud dissipates leaving a processed aerosol population comprised of aerosol reformed after having passed through cloud as drops, others which passed through cloud as interstitial aerosol, and others which may have been formed on exit from the cloud system. In the first two cases, modification may occur through active chemistry within the aqueous volume of the droplet or aerosol, through the take up/loss of gaseous species onto/from the aerosol or drop surfaces prior to entry into cloud or within the cloud, or through collisional capture of other particles at any point in the system. Further changes in the aerosol spectrum can result from the entrainment of air into the system at any point between the measuring sites.

\subsection{ACE-2 HILLCLOUD measurements and sites}

Fig. 2 shows the five major ground based sites used on Tenerife during HILLCLOUD in 1997 in a schematic cross section ( $\mathrm{S}-\mathrm{N})$ through the island (the geographic location of these sites is shown in Fig. 1). Sites TG1, TG2 and TG3 at Taganana, El Bailadero and Paiba respectively formed the three main HILLCLOUD sites. Sites PDH and IZO at Punta del Hidalgo (on the north coast $10 \mathrm{~km}$ to the west of Taganana village) and Izana (on the eastern side of the central volcano in the free troposphere) respectively, were the HILLCLOUD/FREETROPE sites at which measurements common to both experiments were carried out. Fig. 2 also indicates the altitude of these sites in metres above mean sea level. In the summer months (particularly June and July) the prevailing wind approaches the Canary Islands from the northeast, and so sites to the north of the Anaga ridge are on the upwind side of the cap cloud.

Table 1 summarises the full suite of measurements carried out by the different groups within ACE-2 HILLCLOUD during the main experiment of 1997. The names and acronyms of the institutes that participated in the experiment are 


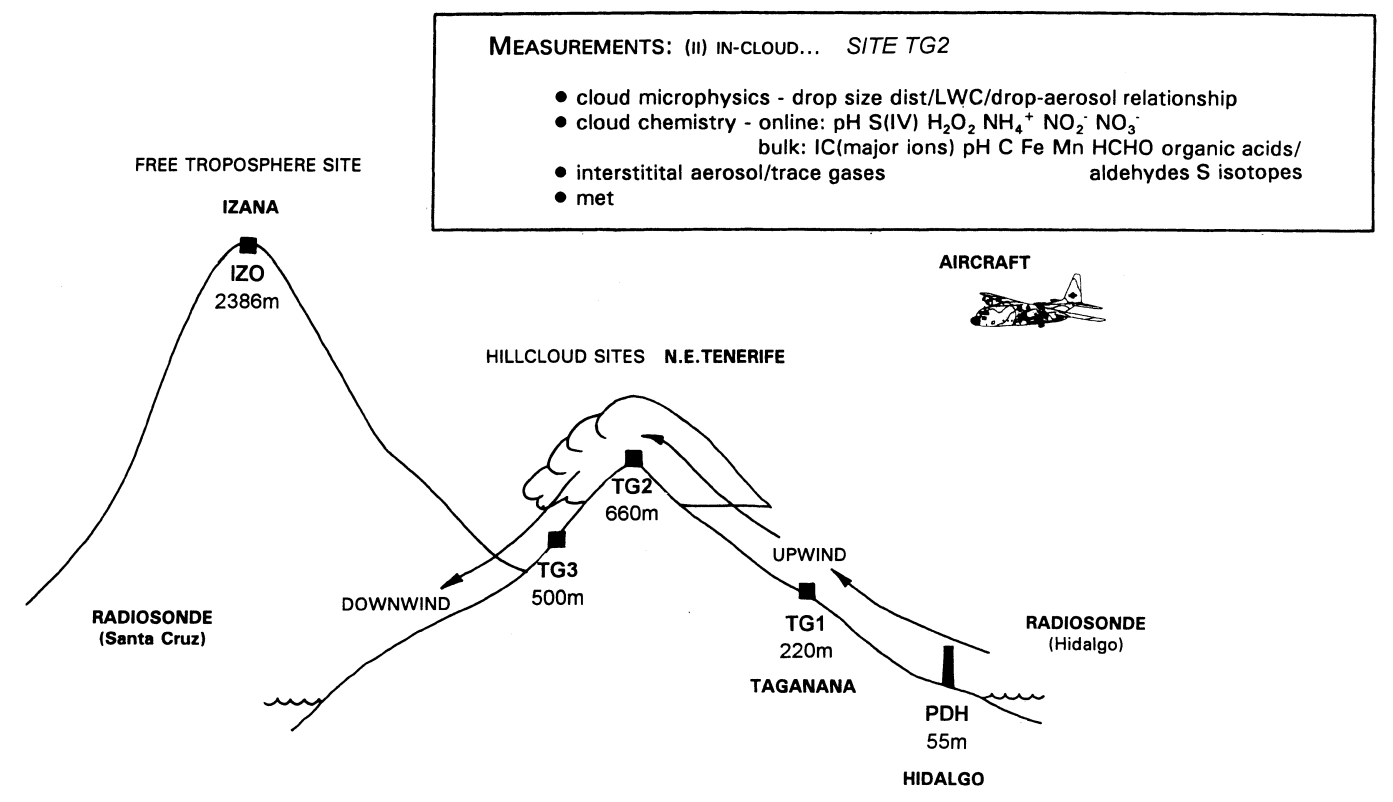

\section{ACE-2 "Hillcloud" measurement sites}

Tenerife June-July 1997
MEASUREMENTS: (I) OUT OF CLOUD... Upwind SITES PDH, TG1 Downwind SITE TG3

- aerosol size distributions/chemistry/hygroscopic properties/CN/CCN - precursor trace gases $\mathrm{SO}_{2} \mathrm{NO}_{x} \mathrm{NO}_{y} \mathrm{NH}_{3} \mathrm{H}_{2} \mathrm{O}_{2} \mathrm{O}_{3} \mathrm{HNO}_{3} \mathrm{HCl}$ DMS NO $\mathrm{NO}_{3} \ldots$ - met

Fig. 2. Schematic south-north cross section through the island of Tenerife.

presented in Table 2. A detailed description of the instruments and techniques used for each measurement may be found in the other papers reporting specific results in this issue.

At the cloud-free sites PDH and TG1 upwind (a lighthouse at PDH and a house in the village of Taganana respectively) and site TG3 downwind (an ex-shooting lodge at Paiba) measurements were made of the size distribution, chemistry and hygroscopic properties of the aerosol together with concentrations of the important precursor trace gases (including $\mathrm{SO}_{2}, \mathrm{NO}_{x}, \mathrm{NH}_{3}, \mathrm{H}_{2} \mathrm{O}_{2}, \mathrm{O}_{3}$, $\mathrm{HNO}_{3}, \mathrm{HCl}$, DMS and $\mathrm{NO}_{3}$ ), i.e., prior to and following passage through the cloud.

At the in-cloud site TG2, El Bailadero, measurements were made of the cloud microphysics (including the drop size distribution, cloud liquid water content LWC, and the droplet-aerosol residue relationship), of the cloud water chemistry and of the properties and concentrations of aerosol and trace gases interstitial to the cloud. Cloud water measurements included online continuous measurements of samples (derived from two high volume bulk passive cloud water collectors) for cloud water $\mathrm{pH}$ and concentrations of $\mathrm{S}(\mathrm{IV})$, $\mathrm{H}_{2} \mathrm{O}_{2}, \mathrm{NH}_{4}^{+}, \mathrm{NO}_{2}^{-}$and $\mathrm{NO}_{3}^{-}$, and batch samples (from bulk and size segregated active cloud water collectors) analysed for $\mathrm{pH}$, conductivity and all major ions by ion chromatography (IC, carried out at the University of La Laguna chemistry laboratories shortly after collection). Other samples were collected using specific active and passive cloud water collectors for the analysis of particular species. Such species included elemental $\mathrm{C}, \mathrm{Fe}, \mathrm{Mn}, \mathrm{HCHO}$, organic acids, aldehydes and sulphur isotopes. Often these samples were stored for later analyses at the home laboratories of participating institutes (although measurements of $\mathrm{pH}$, conductivity and concentrations of $\mathrm{S}(\mathrm{IV})$ and peroxides, if made at all, e.g., CSU collector samples, were performed on site).

Measurements of aerosol and gases were also made by FREETROPE in the free troposphere at IZO (Izana), providing information on the airmass 
Table 1. Measurements carried out at ground-based sites during ACE-2 HILLCLOUD

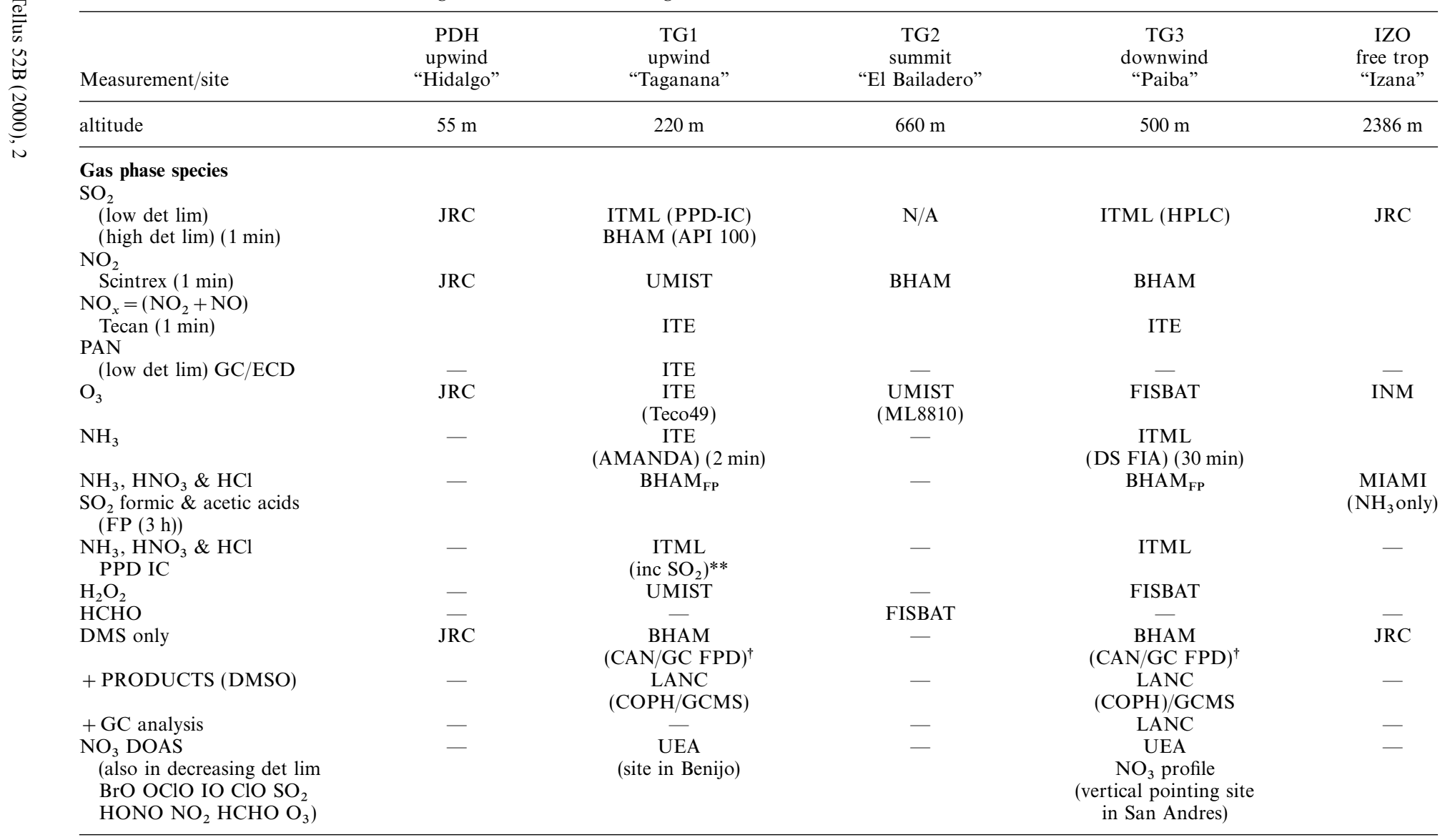

PPD IC = parallel plate denuder ion chromatography, HPLC $=$ Saltzmann technique, high-pressure liquid chromatography, GC FPD = gas chromatography with flame photometric detection, GCMS $=\mathrm{GC}$ mass spectrometry, $\mathrm{FP}=$ filter pack (home lab analysis), $\mathrm{CAN}=$ stainless steel canisters, $\mathrm{COPH}=\mathrm{copher}$ mis chambers, AMANDA = ammonia annular denuder, DS FIA = diffussion scrubber + flow injection analysis), $\mathrm{NB}$ : $* * \mathrm{HNO}_{2}$ not possible (with peroxide scrubber for $\left.\mathrm{SO}_{2}\right) .{ }^{\dagger}$ Time resolution limited by number of cans. 


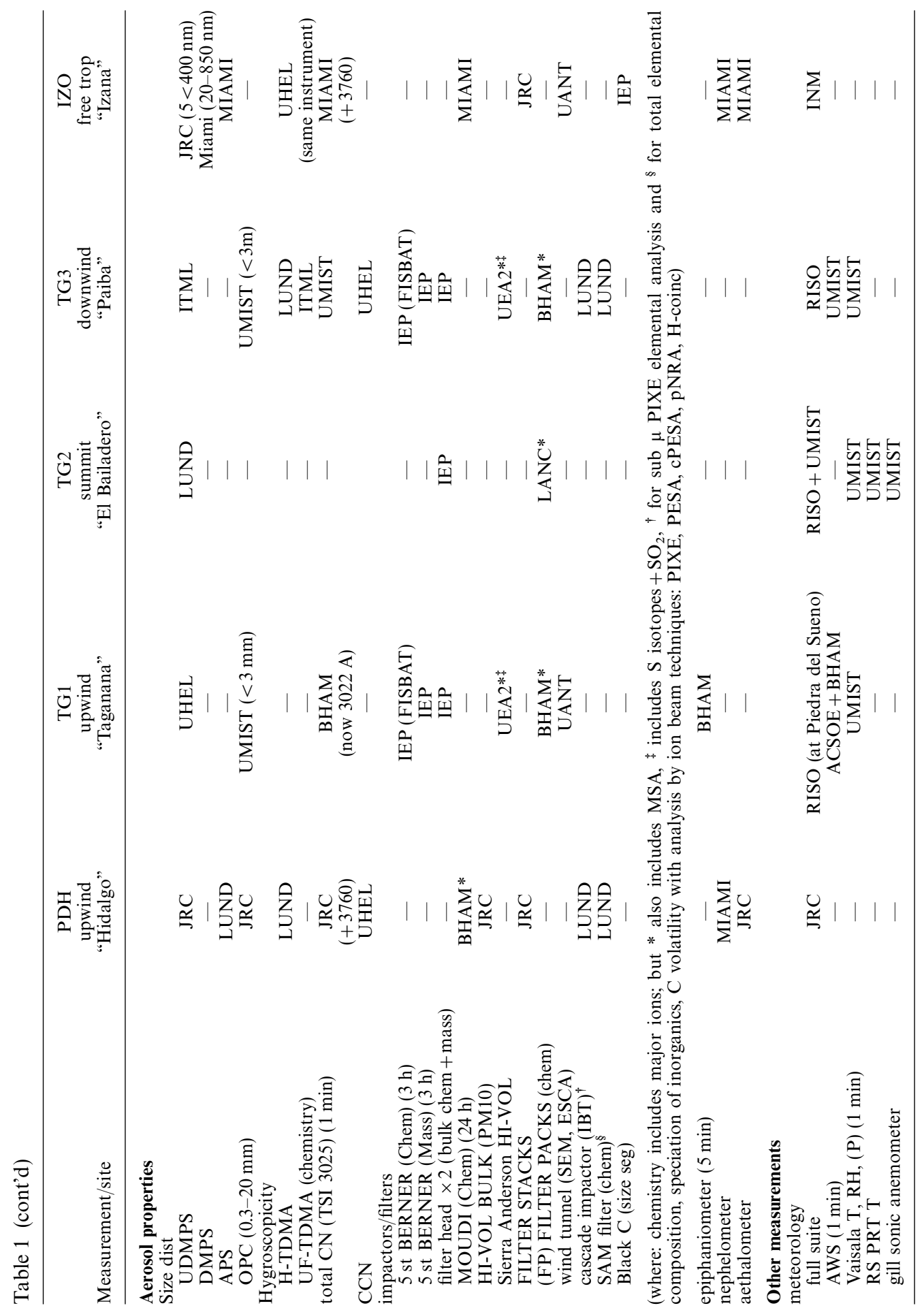

Tellus 52B (2000), 2 


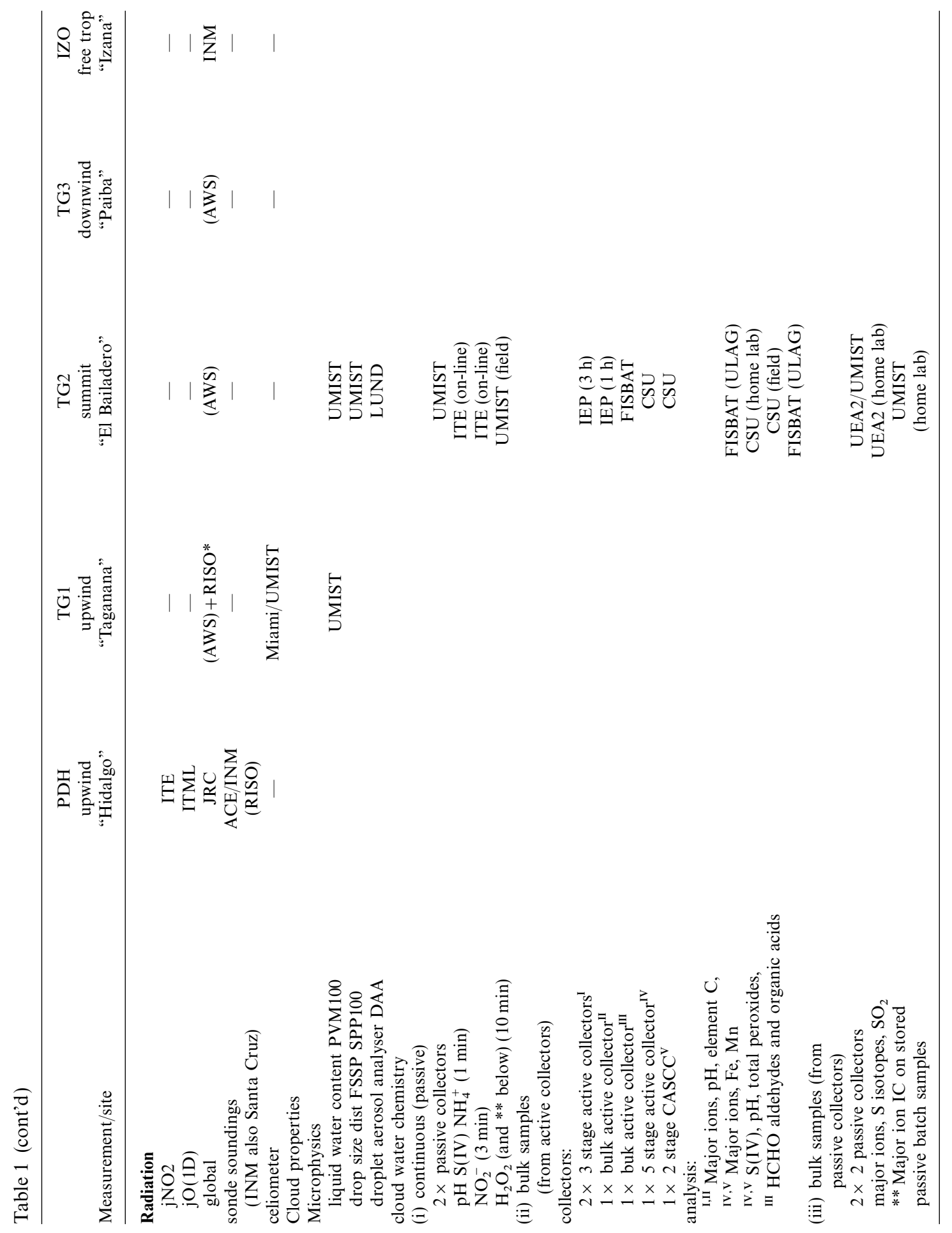

Tellus 52B (2000), 2 
Table 2. Participating institutes in ACE-2 HILLCLOUD

\begin{tabular}{|c|c|c|}
\hline Accronym & Institute & Location \\
\hline UMIST & $\begin{array}{l}\text { University of Manchester Institute of Science and Technology, } \\
\text { Department of Physics. }\end{array}$ & Manchester, UK \\
\hline BНAM & $\begin{array}{l}\text { University of Birmingham, } \\
\text { Institute of Public and Environmental Health }\end{array}$ & Birmingham, UK \\
\hline ITE & Institute of Terrestrial Ecology, Bush Estate, Pencuik & Edinburgh, UK \\
\hline LUND & Lund University, Division of Nuclear Physics & Lund, Sweden \\
\hline ITML & $\begin{array}{l}\text { Air Pollution Laboratory, Institute of Applied Environmental Research, } \\
\text { Stockholm University }\end{array}$ & Stockholm, Sweden \\
\hline UHEL & University of Helsinki, Department of Physics & Helsinki, Finland \\
\hline IEP & Institut fur Experimentalphysik, Universitat Wien & Vienna, Austria \\
\hline FISBAT & $\begin{array}{l}\text { Consilio Nazionale delle Ricerche, Inst. per lo Studio dei } \\
\text { Fenomeni Fisici e Chimici della Bassa ed Alta Atm }\end{array}$ & Bologna, Italy \\
\hline RISO & Risø National Laboratory & Roslilde, Denmark \\
\hline LANC & $\begin{array}{l}\text { Institute of Environmental and Natural Sciences, } \\
\text { University of Lancaster }\end{array}$ & Lancaster, UK \\
\hline UEA & University of East Anglia, School of Environmental Sciences & Norwich, UK \\
\hline CSU & Colorado State University, Department of Atmospheric Science & $\begin{array}{l}\text { Ft. Collins, } \\
\text { Colorado, USA }\end{array}$ \\
\hline UANT & $\begin{array}{l}\text { University of Antwerp, Micro and Trace Analysis Centre (MiTAC), } \\
\text { Department of Chemistry }\end{array}$ & Wilrijk, Belgium \\
\hline $\mathrm{JRC}$ & Environment Institute, EC Joint Research Centre & Ispra, Italy \\
\hline MIAMI & University of Miami & $\begin{array}{l}\text { Miami, } \\
\text { Florida, USA }\end{array}$ \\
\hline INM & $\begin{array}{l}\text { Spanish Meteorological Office } \\
\text { (Centro Meteorológico de Canarias Occidental) }\end{array}$ & $\begin{array}{l}\text { Santa Cruz, } \\
\text { Tenerife, Spain }\end{array}$ \\
\hline ULAG & Department of Chemistry, University of La Laguna & $\begin{array}{l}\text { La Laguna, } \\
\text { Tenerife, Spain }\end{array}$ \\
\hline ACSOE & $\begin{array}{l}\text { UK NERC Consortium, "atmospheric chemistry studies in the } \\
\text { ocean environment" }\end{array}$ & UK \\
\hline
\end{tabular}

possibly being entrained into the top of the cap cloud over the ridge. Standard meteorological measurements (of wind, temperature $T$, relative humidity $\mathrm{RH}$, and radiation) were made at all sites, and also at an additional site between TG1 and TG2 at Piedra del Sueno (Nielsen, 1998). Measurements of the nitrate radical $\mathrm{NO}_{3}$ (and of other species) were made by differential optical absorption spectroscopy (DOAS) from a site at Benijo on the north Anaga coast just to the east of the Taganana cove (Fig. 1). The DOAS light beam- total path length $9.2 \mathrm{~km}$-crossed the bay upwind of any local sources in Taganana at a height of between 70 and $200 \mathrm{~m}$ above sea level. A second vertical pointing DOAS instrument (using sunlight at dawn as a light source) was housed at a house in San Andres on the southeast coast of the Anaga peninsula (due south of TG2).

Balloon sonde launches were carried out at PDH by FREETROPE / HILLCLOUD and use was also made of the regular sonde launches carried out by the Spanish Meteorological Office (INM) from their HQ in Santa Cruz de Tenerife (south-west of the Anaga ridge). These provided the thermodynamic structure of the atmosphere upwind and downwind of the ridge. The UK Meteorological Office's Meteorological Research Flight (MRF) C-130 aircraft (involved in all the ACE-2 activities) also carried out ascent profiles and made similar measurements (to those made at ground based sites) in the boundary layer and free troposphere north of the island, and over the hill cap cloud prior to landing at the north airport on its return from other ACE-2 missions. A full list of measurements made aboard the aircraft can be found in Johnson et al. (2000).

\subsection{ACE-2 HILLCLOUD: operational mode}

Between 18 June and 23 July 1997, HILLCLOUD ran in intensive run mode during suitable 
cloud events, i.e., when site 2 was in cloud for a long enough period to enable at least some of the longer time resolution measurements/samples to be made/collected, e.g., for there to be sufficient time for the collection of a cloud water sample for chemical analysis, or for the collection of aerosol samples by impactor (i.e., in air before and after it is known to have passed through cloud). At other times these and other labour intensive measurements were not made but the experiment continued to run in background monitoring mode, measuring gas concentrations, meteorology and certain aerosol properties (e.g., size distributions and concentrations). Despite frustrated occasions when no cloud enveloped site 2 (but was often present just above the site-but prevented any in-cloud monitoring) eight periods of intensive measurements or "runs" were carried out. These periods are summarised in Table 3.

Because of local sources of pollution, in particular road traffic during the daytime (highlighted by $\mathrm{NO}_{2}$ and $\mathrm{CN}$ measurements made in the precampaign of 1996 and again in 1997) preferred periods for runs were at night. In general, most suitable cloud events were measured, and over the eight runs were carried out in a variety of conditions as indicated by the range of values of some selected parameters summarised in Table 4. These results suggest that runs 1 and 8 were carried out in clean maritime air, characterised by low ozone concentrations, low accumulation mode aerosol number concentrations, low $\mathrm{CN}$ concentrations and low cloud droplet number concentrations. In contrast, runs 2 and 3 were carried out either side of the first ACE-2 pollution event (Verver et al., 2000 ) in air originating over NW Iberia and prior to that over the UK (as indicated by the back trajectory analysis). These runs were characterised by having high ozone, high accumulation mode aerosol and $\mathrm{CN}$ concentrations and above all unexpectedly high cloud droplet number concentrations. Indications of the airmass type in the remaining runs are somewhat unclear. In these cases, which were somewhat intermediate in nature, back trajectory analysis suggests that the air may well have been aged continental and long range transported possibly originating over North America or was at other times affected by mixing with subsiding polluted air possibly from a European outflow.

Analyses of wind speed and direction, thermodynamic parameters and trace gas concentrations (described below) suggest sites TG1, TG2 and TG3 were flow connected during the runs, and that there was little entrainment of free tropospheric air into the system between sites (although it is possible that entrainment occurred between sites TG2 and TG3 for run 6). There are, however, strong indications of entrainment and mixing occurring upstream of the island prior to its measurement at any HILLCLOUD site. These (and many other) results will now be discussed in greater detail.

It should be noted at this point that because of the complexity of multiple site experiments such as HILLCLOUD (involving a very large number of measurements of different type made at separate measurement sites, see Table 1 for HILLCLOUD), it is not realistic to expect that all physical and chemical measurements will be successful at all sites (in-cloud and out of cloud) on all occasions. It is nearly always the case that failures of certain instruments occur from time to time, leading to either a reduction in the quality of or even absence of certain data during these periods. This was true too during the HILLCLOUD experiment. The

Table 3. ACE-2 HILLCLOUD intensive run times

\begin{tabular}{llrl}
\hline Run & Julian day & \multicolumn{1}{c}{ Date } & \multicolumn{1}{c}{ Times } \\
\hline 1 & $182 / 183$ & $(1-2) / 7 / 97$ & $23: 40-06: 30$ \\
2 & $188 / 189$ & $(7-8) / 7 / 97$ & about 20:00-09:30 (poss to 11:30) \\
3 & $189 / 190$ & $(8-9) / 7 / 97$ & about 23:00-07:30 \\
4 & 194 & $13 / 7 / 97$ & about $01: 00-08: 00$ (unmanned batch cloud water) \\
5 & 195 & $14 / 7 / 97$ & about 04:00-09:30 (02:00-09:30 with holes) \\
6 & 198 & $17 / 7 / 97$ & $02: 00-09: 30$ \\
7 & 201 & $20 / 7 / 97$ & about $14: 30-24: 00$ (cloud returned $02: 00-)$ \\
8 & 203 & $22 / 7 / 97$ & \\
\hline
\end{tabular}

Tellus 52B (2000), 2 
Table 4. Typical values of some gas, aerosol and cloud microphysical and chemical measurements during runs

\begin{tabular}{|c|c|c|c|c|c|c|c|c|c|c|}
\hline \multirow[b]{2}{*}{ Run \# } & \multirow[b]{2}{*}{$\begin{array}{c}\mathrm{O}_{3} \mathrm{TG}^{2} \\
\text { (ML8810) } \\
\text { (ppbv) }\end{array}$} & \multirow[b]{2}{*}{$\begin{array}{l}\mathrm{H}_{2} \mathrm{O}_{2}(\mathrm{~g}) \mathrm{TG} 1 \\
(\mathrm{ppbv})\end{array}$} & \multirow[b]{2}{*}{$\begin{array}{l}\mathrm{SO}_{2} \mathrm{TG} 1 \\
\text { (filter pack) } \\
\quad\left(\mathrm{cm}^{-3} \text { ) }\right.\end{array}$} & \multirow[b]{2}{*}{$\begin{array}{c}\mathrm{N}_{\mathrm{ACC}} \mathrm{TG} 1 / 3 \\
\text { (ASASP-X) } \\
\text { (ppbv) }\end{array}$} & \multirow[b]{2}{*}{$\begin{array}{c}\mathrm{N}_{\text {drop }} \text { TG2 } \\
\text { (FSSP) } \\
\left(\mathrm{cm}^{-3}\right)\end{array}$} & \multirow[b]{2}{*}{$\begin{array}{l}\text { CN TG3 } \\
(3025) \\
\left(\mathrm{cm}^{-3}\right)\end{array}$} & \multicolumn{3}{|c|}{$\begin{array}{c}\text { From integrating filter packs, } \\
\text { FPs, at TG1 }\end{array}$} & \multirow[b]{2}{*}{$\begin{array}{l}\text { Back trajectory } \\
\text { (from KNMI) } \\
\text { ( } 5 \text { day) .. from }\end{array}$} \\
\hline & & & & & & & $\begin{array}{l}\text { chloride } \\
\text { loading } \\
\left(\mu \mathrm{g} \mathrm{m}^{-3}\right)\end{array}$ & $\begin{array}{l}\text { sulphate } \\
\text { loading } \\
\left(\mu \mathrm{g} \mathrm{m}^{-3}\right)\end{array}$ & $\begin{array}{c}\text { nitrate } \\
\text { loading } \\
\left(\mu \mathrm{g} \mathrm{m}^{-3}\right)\end{array}$ & \\
\hline run 1 & $\begin{array}{c}15 \rightarrow 25 \\
( \pm 1)\end{array}$ & $\begin{array}{l}1.1 \rightarrow 0.4 \rightarrow 1.0 \\
\quad( \pm 0.2)\end{array}$ & $18 \rightarrow 8$ & $\begin{array}{c}200 \\
( \pm 40)\end{array}$ & $\begin{array}{c}100-250 \\
( \pm 50)\end{array}$ & $\begin{array}{l}300^{\ddagger} \text { (up to } \\
\quad<1500)\end{array}$ & $1.0-6.0$ & $0.7-2.0$ & $0.3-0.5$ & $\begin{array}{l}\text { All: Mid Atlantic } \\
\text { (due W) LONG }\end{array}$ \\
\hline run 2 & $\begin{array}{c}36 \rightarrow 45 \rightarrow 43 \\
\quad( \pm 1)\end{array}$ & $\begin{array}{l}1.3 \rightarrow 0.6 \rightarrow 0.8 \\
\quad( \pm 0.15)\end{array}$ & $42 \rightarrow 190$ & $\begin{array}{c}1200 \rightarrow 1500 \rightarrow \\
1300 \\
( \pm 200)\end{array}$ & $\begin{array}{l}1000-2800^{\dagger} \\
( \pm 200)\end{array}$ & $2000 \rightarrow 3500^{\ddagger}$ & $9.0-13.0$ & $7.0-10.0$ & $3.4 \rightarrow 4.5$ & $\begin{array}{l}\text { L: NW Iberia } \\
\mathrm{M} / \mathrm{U} \text { : from S-At } \\
\text { or Africa }\end{array}$ \\
\hline run 3 & $\begin{array}{c}35 \rightarrow 40 \rightarrow 35 \\
\quad( \pm 1)\end{array}$ & $\begin{array}{c}0.75 \\
( \pm 0.1)\end{array}$ & $48 \rightarrow 0$ & $\begin{array}{c}1100 \rightarrow 900 \rightarrow \\
500 \\
( \pm 200)\end{array}$ & $\begin{array}{c}1700-400^{\dagger} \\
( \pm 200)\end{array}$ & $700 \rightarrow 200^{\ddagger}$ & $9.0-14.0$ & $5.0-9.0$ & $3.8 \rightarrow 1.7$ & $\begin{array}{l}\text { L: NW Iberia/UK } \\
\mathrm{M} / \mathrm{U} \text { : from S-At } \\
\text { or Africa }\end{array}$ \\
\hline run 4 & $\begin{aligned} & 20 \rightarrow 17 \\
&( \pm 1)\end{aligned}$ & - & $20 \rightarrow 72$ & $\begin{array}{l}350 \\
( \pm 50)\end{array}$ & $\begin{array}{c}350-400 \\
( \pm 80)\end{array}$ & $500^{\S}$ & 3.0 & 2.3 & $0.9-1.0$ & $\begin{array}{l}\text { All: NW At } \\
\text { V. LONG } \\
\text { U: poss E USA }\end{array}$ \\
\hline run 5 & $\begin{aligned} 20 & \rightarrow 16 \rightarrow 20 \\
& ( \pm 1)\end{aligned}$ & $\begin{array}{l}1.2 \rightarrow 0.8 \\
( \pm 0.15)\end{array}$ & $30 \rightarrow 71$ & $\begin{array}{l}350 \rightarrow 400 \\
\quad( \pm 50)\end{array}$ & $\begin{array}{l}300-450 \\
( \pm 80)\end{array}$ & $500 \rightarrow 800^{\ddagger}$ & 2.0 & 2.7 & $0.8-1.3$ & $\begin{array}{l}\text { All: NNW At } \\
\text { V. LONG } \\
\text { U: LONG W At via } \\
\text { NW At }\end{array}$ \\
\hline run 6 & - & $\begin{array}{c}1.3 \rightarrow 0.6 \\
( \pm 0.3)\end{array}$ & $3 \rightarrow 53$ & $\begin{array}{c}300 \rightarrow 700 \rightarrow \\
400 \\
( \pm 50)\end{array}$ & $\begin{array}{l}400-650 \\
( \pm 100)\end{array}$ & $500 \rightarrow 1000^{\ddagger}$ & $5.0-6.0$ & $3.0-5.2$ & $0.8-2.0$ & $\begin{array}{l}\text { L: poss NW Ib'a } \\
\text { U: mid At SHORT }\end{array}$ \\
\hline run 7 & $\begin{array}{c}29 \\
( \pm 1)\end{array}$ & - & 9 & $\begin{array}{c}250 \\
( \pm 50)\end{array}$ & $\begin{array}{c}200-250 \\
( \pm 100)\end{array}$ & 600 & $7.0-10.0$ & 3.3 & $0.7-0.9$ & $\begin{array}{l}\text { L/M: NW Ib’a } \\
\text { U: mid At }\end{array}$ \\
\hline run 8 & $\begin{array}{c}15 \rightarrow 20 \\
( \pm 1)\end{array}$ & $\begin{array}{c}0.9 \rightarrow 0.8 \\
(+2.2,-0.2)\end{array}$ & $6 \rightarrow 40$ & $\begin{array}{l}50 \rightarrow 150 \\
( \pm 50)\end{array}$ & $\begin{array}{c}50 \rightarrow 150 \\
( \pm 50)\end{array}$ & $300^{\ddagger *}$ & $1.0-7.0$ & $0.5-2.6$ & $0.2-0.8$ & $\begin{array}{l}\text { L/M: N At (W of Eire) } \\
\text { U: mid At }\end{array}$ \\
\hline
\end{tabular}

Key: arrows $(\rightarrow)$ indicate trend change, dashes $(-)$ indicate general range of values. ${ }^{\dagger} \mathrm{N}_{\text {drop }}$ are DAA drop numbers (see Martinsson et al., 2000)). $\mathrm{CN}{ }^{\ddagger}$ very nois after $4 \mathrm{am},{ }^{\S}$ after $6 \mathrm{am},{ }^{*} *$ before $10 \mathrm{pm}$. Back trajectories (Verver et al., 2000): $\mathrm{L}=$ low level $(>760 \mathrm{mbar}) ; \mathrm{M}=\operatorname{mid}$ level; $\mathrm{U}=\operatorname{upper}$ level $(<500 \mathrm{mbar}) ; \mathrm{At}=$ Atlantic Ocean; Ib'a = Iberian Peninsula. 
consequence of this is that it is impossible to present complete closure studies on all aspects of the cloud-aerosol system at all times. Because of this, in the analysis which follows, results which best show the processes occurring within the aerosol-cloud system in the different conditions are often selected from different intensive runs in order to clarify the issues (rather than attempting to present complete closure for individual case studies which would otherwise require the use of these absent or below standard data). Further to this, certain processes will only have sufficient magnitude to be observed when certain input conditions to the system are present, and will not therefore be evident in every case study. However, by careful analysis of the results from the different cases, and by using process modelling to help in the analysis and interpretation of data, it is hoped that many of the more important processes which are active within the aerosol-cloud system can be identified and described in this overview and accompanying papers.

\section{Main results from ACE-2 HILLCLOUD}

\subsection{Meteorology, airflow and entrainment}

The meteorological situation for the whole of the ACE-2 experiment is described in detail by Verver et al. (2000). The source regions of air arriving at Tenerife in the MBL can vary considerably during the summer months. Verver et al. present an analysis of modelled back trajectories to determine the recent history of the air arriving at Tenerife during ACE-2. Table 4 summarises the airmass origins for the eight HILLCLOUD intensive run periods.

In order that the measurements made at the different HILLCLOUD sites could be compared directly (e.g., for evidence of aerosol spectrum evolution), a post-experiment investigation was carried out to examine (i) whether the air flow between the HILLCLOUD sites was "connected" during run periods, and (ii) whether this airflow system was closed i.e., unaffected by entrainment from the free troposphere between any of the HILLCLOUD sites. Study of the wind field and concentrations of unreactive trace gases (e.g., $\mathrm{NO}_{2}, \mathrm{O}_{3}$ ) at each of the hill cloud sites showed that the flow was indeed connected between the sites at all times during the cloud events. This was confirmed by modelling studies of the airflow. Analysis of thermodynamic parameters also showed that the effects of entrainment between the sites was very small. Two parameters included in this investigation were the wet equivalent potential temperature and the total water mixing ratio, $\theta_{\mathrm{q}}$ and $Q$ respectively (Paluch, 1979). For a closed system (i.e., unaffected by losses such as those resulting from precipitation or through entrainment of air into the system) these parameters should be conserved across the hill between measurement sites. This was found to be the case for each of the HILLCLOUD runs. This is illustrated in Figs. 3, 4, which show the variation of these parameters with time for sites TG1, TG2 and TG3 during run 2. The decrease in $Q$ and $\theta_{\mathrm{q}}$ at TG3 between 00:00-02:00 represents a change of less than $5 \%$ by volume. Although concentrations of $\mathrm{NO}_{2}$ (and also condensation nuclei, $\mathrm{CN}$ ) were often affected by local influences, it was sometimes possible to use such contamination spikes as a tracer between consecutive TG sites. Better still were broader features, believed to be produced by ship traffic passing some distance to the north of the island, which often were observed (with suitable time lags) at all the HILLCLOUD sites indicating flow connection. Fig. 5 shows one such example for $\mathrm{NO}_{2}$ measured at TG1 and TG3 on 2 July (during run 1). Of interest here is the period between 1:30 and 3:30.

Although there appears to be little significant entrainment through the top of the boundary layer between HILLCLOUD sites during runs, there is strong evidence of entrainment and mixing occurring upstream of the island. A Paluch thermodynamic diagram (Paluch, 1979) for run 2 is presented in Fig. 6. In this plot of $Q$ against $\theta_{\mathrm{q}}$, the points representing data from the three $\mathrm{TG}$ sites at any particular time lie in close proximity to each other (implying little mixing occurring between the TG sites at this specific time). In addition, these data groups also lie close to points representing the lowest regions of the environmental profile on occasions when ascent data from sondes launched from PDH were simultaneously available to calculate $Q$ and $\theta_{\mathrm{q}}$ in this way (NB. at least one sonde was launched at PDH per HILLCLOUD run). However, the position of data groups (comprised of simultaneous values of $Q$ and $\theta_{\mathrm{q}}$ from the three TG sites) varies in time, and suggests mixing was occurring between the free troposphere and the boundary layer upstream of the island. Profiles of gases and 
Connected Flow Analysis: Total Water Mixing Ratio (Run 2)

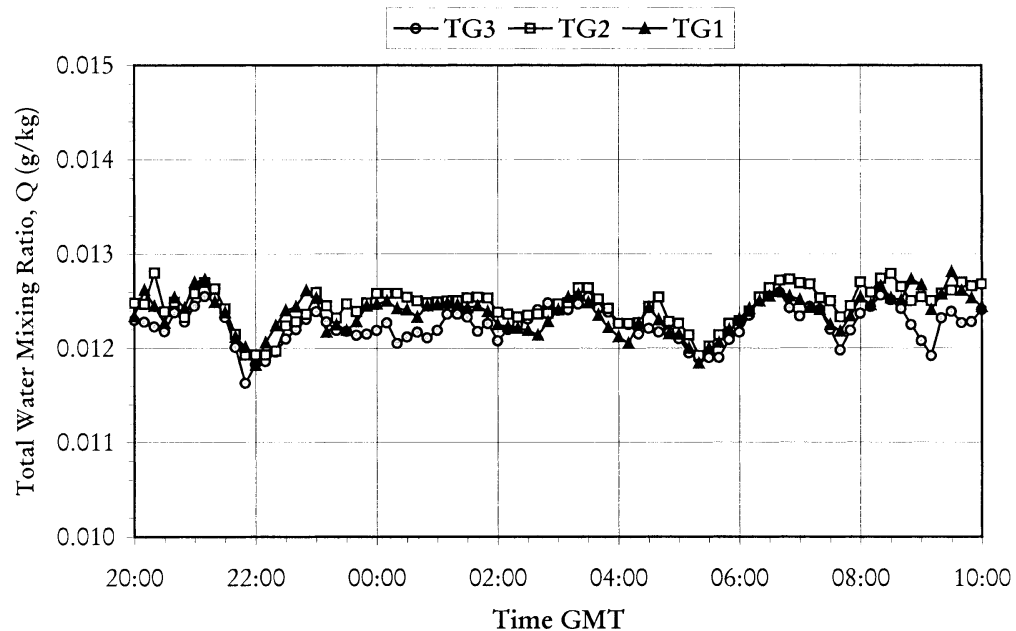

Fig. 3. Total water mixing ratio $Q(\mathrm{~g} / \mathrm{kg})$ for HILLCLOUD run 2 .

Connected Flow Analysis: Wet Equivalent Potential Temperature

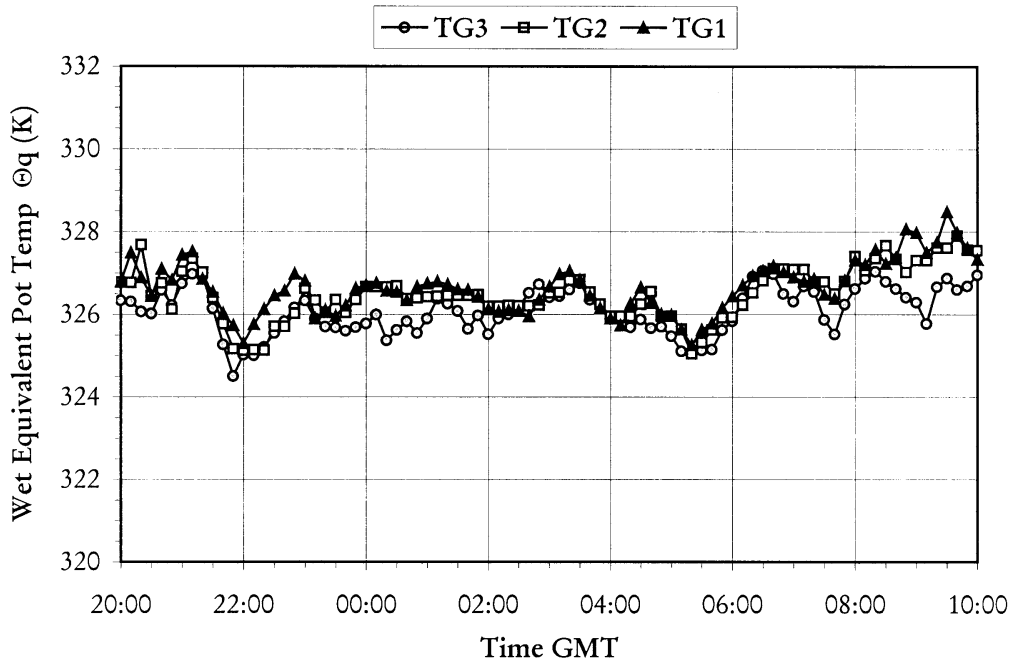

Fig. 4. Wet equivalent potential temperature $\theta q(\mathrm{~K})$ for HILLCLOUD run 2.

aerosol from the MRF C-130 aircraft (Johnson et al., 2000), together with measurements at the free troposphere site at Izana showed that this entrainment introduced hydrogen peroxide and ozone, generally reduced the boundary layer aerosol concentrations, and through aerosol exchange with the free troposphere changed the composition and associated properties of the aerosol in the MBL.

In addition to intensive run periods, the con- nected flow analysis was extended to determine flow connection between the sites in cloud free conditions. Such periods could be used for the intercomparison of instrumentation making similar measurements at each of the ground based sites (e.g., for comparison of Differential Mobility Particle Sizer (DMPS) aerosol size distributions made at PDH, TG1, TG2 and TG3). The analysis indicted that connected flow between the sites 


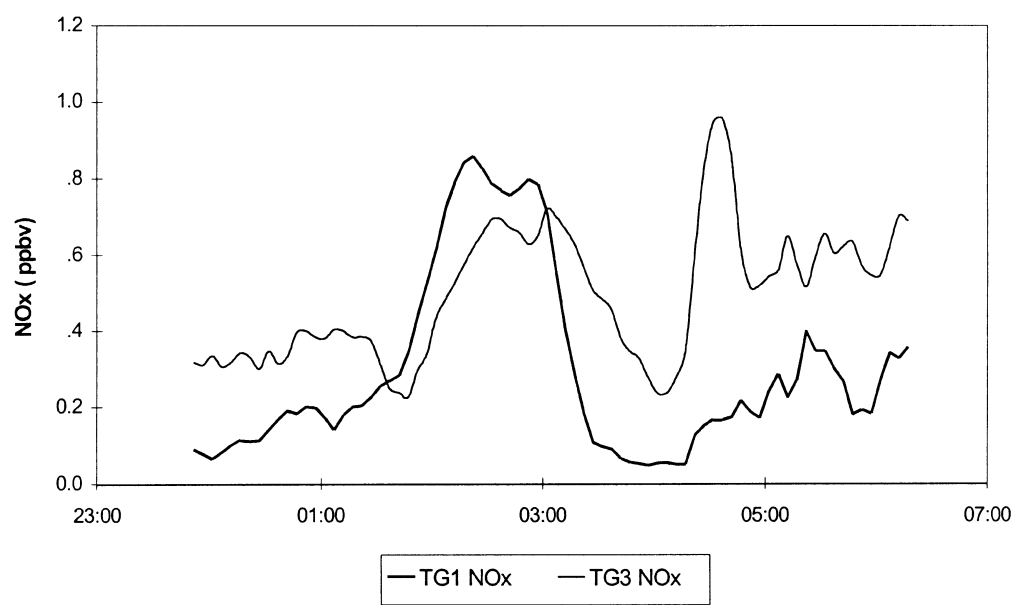

Fig. 5. Co-variation of $\mathrm{NO}_{x}$ at TG1 and TG3 during run 1. Of interest is the broad feature observed at night (01:30 to $04: 30$ ), believed to be a ship plume.

Entrainment Analysis: Paluch Diagram (Run 2, 00:00z)

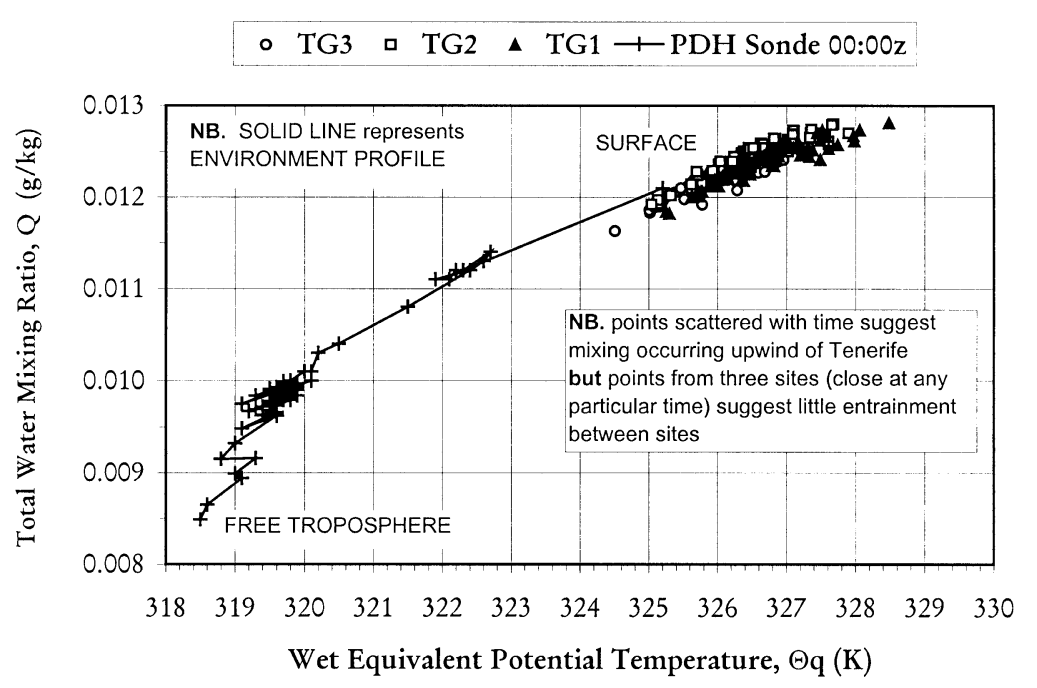

Fig. 6. Paluch thermodynamic diagram for HILLCLOUD run 2 (see text for details).

occurred very infrequently during daylight cloud free conditions (possibly due to the effects of solar heating setting up local convection), and also on cloud free nights (due to the effects of strong radiative cooling). However, instrument intercomparisons were possible during brief cloud-free intervals within runs, where airflow connection between sites was maintained. Fig. 7 shows an intercomparison of DMPS aerosol spectra for one such cloud free connected flow period during run 2 . The results of measurement intercomparisons of this type have been incorporated into the quality assessment and control procedures employed to validate data sets prior to their submission to the ACE-2 data archive (Raes et al., 2000).

\subsection{Gas concentrations}

Measurements of most trace gases were made throughout the experiment. Table 5 summarises 
DMPS Size Distribution Comparison - (Run 2, 07/07/97 21:40z)

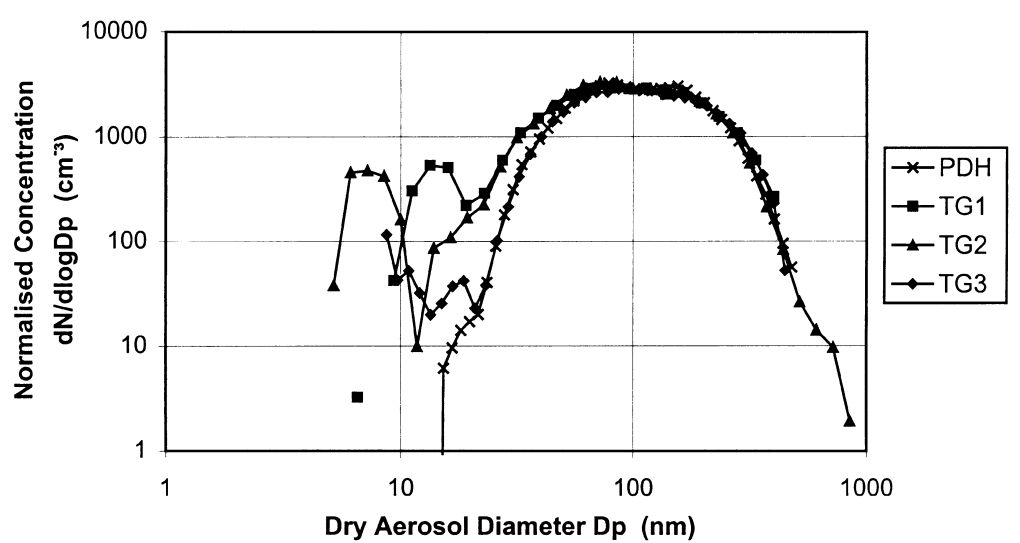

Fig. 7. Comparison of DMPS aerosol spectra measured at TG1, TG2 and TG3 sites during brief cloud free period in HILLCLOUD run $2(07 / 07 / 97)$ at about 21:40.

Table 5. Typical gas concentrations observed during ACE-2 HILLCLOUD

\begin{tabular}{|c|c|}
\hline Species & Concentrations \\
\hline $\mathrm{NO}_{2}$ & $15-100$ ppt (night-time) \\
\hline $\mathrm{NO}_{3}^{\circ}$ & $\begin{array}{l}1-4 \mathrm{ppt} \text { (clean maritime), } 1-2 \mathrm{ppt} \text { (polluted } \\
\text { continental) }\end{array}$ \\
\hline $\mathrm{H}_{2} \mathrm{O}_{2}$ & $0.1-3 \mathrm{ppb}$ (typically $0.5-1.5 \mathrm{ppb}$ ) \\
\hline $\mathrm{O}_{3}$ & $13-50 \mathrm{ppb}$ (higher during polluted events) \\
\hline $\mathrm{NH}_{3}$ & $0.2-0.4 \mathrm{ppb}$ (background) \\
\hline $\mathrm{SO}_{2}(\mathrm{FP})^{*}$ & $34 \mathrm{ppt}(0-190 \mathrm{ppt})$ \\
\hline $\mathrm{HNO}_{3}(\mathrm{FP})$ & $59 \mathrm{ppt}(9-209 \mathrm{ppt})$ \\
\hline $\mathrm{HCl}(\mathrm{FP})$ & $108 \mathrm{ppt}(0-359 \mathrm{ppt})$ \\
\hline
\end{tabular}

where: $\mathrm{FP}=$ filter pack measurement $($ at TG1); *good agreement with higher time resolution techniques (e.g., Saltzmann - HPLC; parallel plate denuder - PPD IC).

the observed concentration range of some of these gases.

The ozone concentrations observed at all sites (often strongly correlated with fine particle concentrations) were believed to be governed predominantly by airmass origins rather than local production/destruction in the gas phase, since much higher concentrations were present during periods of pollution outflow from Europe (Table 4). This is consistent with the photochemical production of ozone in the polluted plume, although preliminary analysis suggests daytime photochemical destruction of ozone was occurring within the low background $\mathrm{NO}_{x}$ environment present on Tenerife (away from local sources) throughout the experiment. Since this leads also to production of hydrogen peroxide, it suggests a source for some of the copious levels of peroxide (generally between 0.5 and $1.5 \mathrm{ppbv}$ ) observed during the campaign. This important aqueous phase oxidant of S(IV) to sulphate in cloud water was thus present in abundance for this purpose throughout the period of observations and varied little with airmass origin (Table 4).

$\mathrm{NO}_{x}$ measurements showed a strong diurnal trend with much higher average concentrations (of several ppb) occurring during the day. Daytime concentrations showed rapid fluctuations, related to the local sources (mostly vehicle exhaust fumes). These "contamination spikes" (of sometimes $>20$ ppbv) were generally highly correlated with similar spikes in $\mathrm{CN}$ concentration. At nighttime, background concentrations of $\mathrm{NO}_{x}$ were generally very low, at or below detection limits (i.e., mainly $<0.1 \mathrm{ppb}$ ), and spikes were almost entirely absent between $10 \mathrm{pm}$ and $4 \mathrm{am}$ local time. Periods of enhanced nighttime concentrations (of a few hours duration) were thought to be related to the advection of dispersed plumes generated by ship traffic passing by to the north of the island. Use was made of these broader features to aid analysis of flow connection between sites (as in Fig. 5).

Measurements of the nitrate radical $\mathrm{NO}_{3}^{*}$, were made by DOAS (using a system originally developed by Plane and Nien (1992) and described 
in detail by Allan et al., 1999) on 14 nights between 28 June and 22 July 1997. Typical profiles of $\mathrm{NO}_{3}$, formed from the reaction of $\mathrm{NO}_{2}$ with $\mathrm{O}_{3}$, were observed with nighttime maxima. Concentrations of between 1 and $20( \pm 0.5) \mathrm{ppt}$ were seen in both 'clean marine' air masses and those advected to Tenerife from continental Europe. However, all $\mathrm{NO}_{3}^{\cdot}$ disappeared shortly after sunrise due to rapid photolysis. These data were used, in conjunction with concurrent measurements of $\mathrm{NO}_{2}$ and $\mathrm{O}_{3}$, to retrieve steady state lifetimes of $\mathrm{NO}_{3}$ of between 5 and $70 \mathrm{~min}$. A box model (Allan et al., 1999), constrained by measurements, was used to investigate the behaviour of the nitrate radical. The results suggest that the reaction between $\mathrm{NO}_{3}^{*}$ and di-methyl sulphide (DMS) is always the dominant loss mechanism for $\mathrm{NO}_{3}$ in these data. When DMS was present in concentrations of between 50 and $70 \mathrm{ppt}$ the percentage of $\mathrm{NO}_{3}$ loss due to reaction with DMS was of the order of 80 to $90 \%$. Losses of $\mathrm{NO}_{3}$ via the heterogeneous loss of $\mathrm{N}_{2} \mathrm{O}_{5}$ did not contribute significantly to the loss of $\mathrm{NO}_{3}^{-}$even on the night of 7-8 July when the aerosol surface area increased substantially. Nitric acid production rates of between 6 and $26 \mathrm{ppt} \mathrm{h}^{-1}$ were derived from the $\mathrm{NO}_{3}$ losses calculated in the box model, due predominantly to the reaction of $\mathrm{NO}_{3}^{-}$with DMS. These rates were comparable to, or larger than, the production rates of $\mathrm{HNO}_{3}$ by reaction of $\mathrm{NO}_{2}$ with $\mathrm{OH}$ during the day for similar $\mathrm{NO}_{x}$ concentrations of between 100 and 300 ppt.

Ammonia concentrations were measured at all three out of cloud sites, and at TG2 briefly during a cloud free period. These are described in detail by Milford et al. (2000). It was apparent that some local sources of ammonia did exist on the island particularly at TG1 and TG3, where significant local gradients were observed close to the surface (Milford et al.). Nevertheless, the ammonia in the clean air sector measured at the coast was clearly derived from the sea-surface and not the island (Milford et al.). This was then advected into the island and was the predominant contribution to the ammonia concentration entering the cloud system under investigation (as was apparent during the brief cloud free measurements made at TG2). Milford et al. also find evidence for outgassing of ammonia from ammonium rich aerosol on occasions between TG1 and TG3. The results of modelling studies by Flynn et al. (2000) of pro- cessing of aerosol through cloud are able to support these observations in low ammonia high ammonium loading regimes.

Sulphur dioxide concentrations measured at the HILLCLOUD sites were clearly of local natural origin. They showed little correlation with airmass origin and little change in concentration due to local pollution sources. Both long time integration (3-h) filter pack measurements and more sophisticated (low detection limit high time resolution) measurements (e.g., by the Saltzman technique) showed similar averaged results. In contrast, both $\mathrm{HCl}$ and $\mathrm{HNO}_{3}$ concentrations were higher during polluted events. Some nitric acid was produced by the reaction of $\mathrm{NO}_{3}$ with DMS (Allan et al., 1999), but neither this route nor estimations of production via the reaction of $\mathrm{NO}_{2}$ with $\mathrm{OH}^{\circ}$ are able to account for the levels of $\mathrm{HNO}_{3}$ observed. In view of this, and of the short lifetime of $\mathrm{HNO}_{3}$ gas in the atmosphere (of a few hours), it is inferred that the most likely origin of the $\mathrm{HNO}_{3}$ observed is from outgassing from nitrate rich aerosol (also present in higher loadings during polluted events). The $\mathrm{HCl}$ concentrations observed are similarly inferred to originate from outgassing from chloride rich aerosol upon/within which reactions have occurred (such as oxidation of $\mathrm{SO}_{2}$ to produce sulphate and also following take-up of nitric acid) as this is the only likely source of $\mathrm{HCl}$ in this remote marine region. Evidence for outgassing of $\mathrm{HNO}_{3}$ and $\mathrm{HCl}$ as aerosol are processed by cloud is provided by Flynn et al. (2000)

Organic acid concentrations were highly variable at TG1 and TG3 (ranging from background concentrations of less than $0.5 \mu \mathrm{g} \mathrm{m}^{-3}$ to spikes at different times - of greater that 2 and $10 \mu \mathrm{g} \mathrm{m}^{-3}$ for formic and acetic acids respectively). Hence concentrations were probably controlled by local emissions (e.g., biomass burning) and/or production during atmospheric reactions.

\subsection{Aerosol properties}

3.3.1. Aerosol size distributions. Measurements of the aerosol size distributions upstream and downstream of the hill cap cloud were made over an extensive size range, generally from $3 \mathrm{~nm}$ up to $3 \mu \mathrm{m}(20 \mu \mathrm{m}$ at $\mathrm{PDH})$. Two major techniques were employed. For aerosol in the ultrafine and fine particle size ranges electrostatic mobility techniques were used, and for larger aerosols in the 
accumulation mode and mass mode size ranges (above $0.1 \mu \mathrm{m}$ ) laser light scattering techniques were used. Differential mobility particle sizers (DMPSs) were deployed at all ground based sites generally scanning over the size range 3 to about 400-500 nm (see Martinsson et al., 2000 for details). PMS Axially Scattering Aerosol Spectrometer Probes (ASASP-X devices) measuring over the size range $0.1-3 \mu \mathrm{m}$ were deployed at TG1 and TG3 (while a TSI aerosol particle sizer APS measuring up to $20 \mu \mathrm{m}$ was deployed at PDH). Measurements were also made of the interstitial aerosol in-cloud at TG2 (using a DMPS measuring from 3 to $850 \mathrm{~nm}$ and a droplet aerosol analyser, DAA - see Martinsson et al, 2000).

In general, the ASASP-X data show close agreement in the distribution of dry aerosol sizes between the upwind and downwind sites during periods of flow connection. Since intensive HILLCLOUD "runs" were confined to these periods, a comparison of the ASASP-X data before and after passing through cloud is able to show any changes in the aerosol size distribution (in the accumulation mode size range) brought about by cloud processing, i.e., through the addition of soluble material to, or the redistribution of soluble material between, aerosol activated into cloud drops during passage through the cloud. However, the only significant indications of this occurring were observed during HILLCLOUD run 1, as shown in Fig. 8. Run 1 was carried out in clean maritime conditions. During the other runs, the upwind and downwind size distributions show excellent agreement below $1 \mu \mathrm{m}$ as shown in Fig. 9 for run 2 (above this size the poor counting statistics of larger particles means that channel concentrations are subject to large uncertainties). Similar close agreement was observed during connected flow periods when cloud was absent as shown in Fig. 10 for run 5 (during a hole in the cloud).

Much evidence suggests aerosol much smaller than $0.1 \mu \mathrm{m}$ were being activated into cloud drops during ACE-2 HILLCLOUD (i.e., from the DAA, which relates cloud drops to their dry residue sizes, and from a comparison of the upwind TG1 and interstitial TG2 DMPS aerosol size distributions. Both suggest aerosol were often activating down to $30-60 \mathrm{~nm}$ to form cloud drops, Martinsson et al.; 2000, Flynn et al., 2000). Since the effects of cloud processing are most readily observed within the smallest aerosol categories activated (i.e., because they are prone to the largest relative changes in soluble mass following processing) then it is quite conceivable that the biggest effects of aerosol modification in terms of a change in aerosol size may well have been out of range of observation by the ASASP-X on most occasions.

Fig. 11 presents a comparison of DMPS aerosol spectra measured upwind, in-cloud and downwind during run 8 . It can be seen from the interstitial TG2 spectrum that aerosol have activated down to $\sim 30 \mathrm{~nm}$ in this clean maritime case (i.e., having activated to form cloud drops they are now missing from the scan). Comparing downwind and upwind spectra, there is strong evidence of aerosol modification in the size range 30 to $100 \mathrm{~nm}$ following passage through the cap cloud (allowing for problems associated with knowing the exact sample volume of the TG3 instrument, i.e., the operators reported mass-flow controller problems causing a varying sample volume. This was corrected for by normalising the number concentration of aerosol in the Aitken mode to that of the upwind spectrum, and by applying this correction factor across the full TG3 spectrum). The growth of some of the smallest aerosol activated has taken place to fill in the dip that was present in the upwind bimodal spectrum. This bimodality is a characteristic of in-cloud processing of aerosol (which must have already occurred upwind of Tenerife), as activated aerosol in the smallest size ranges gain soluble material and grow to larger sizes leaving behind a "hole" in the spectrum. However, in this case the updraughts in the cap cloud have generated a higher supersaturation and hence activated aerosol down to smaller sizes than in the processing cloud upwind of Tenerife. In both this and the ASASP-X (Fig. 8) examples, the aerosol growth is believed to have occurred as a result of a complexity of chemical processes including the take-up of acid gases $\mathrm{HCl}$ and $\mathrm{HNO}_{3}$ (fixed in the aerosol phase by ammonia) and the production of sulphate by the aqueous phase oxidation of $\mathrm{SO}_{2}$. Evidence for these mechanisms from the aerosol chemistry measurements and modelling studies of Flynn et al. (2000) will be discussed below.

3.3.2. Aerosol hygroscopic properties. Two identical hygroscopic tandem differential mobility 


\section{ACE-2 Hillcloud: ASASP-X Aerosol Size Distributions TG1-TG3 comparison (Run 1 02/07/97: 04:00)}

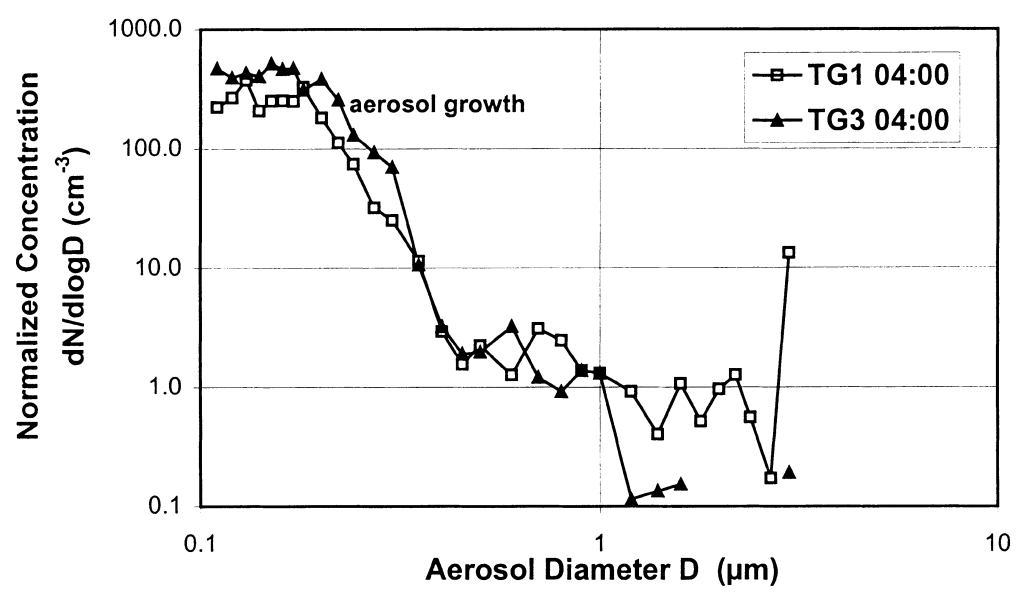

Fig. 8. Comparison of upwind and downwind accumulation mode aerosol spectra during HILLCLOUD run 1.

\section{ACE-2 Hillcloud: ASASP-X Aerosol Size Distributions TG1-TG3 comparison (Run 2 07/07/97: 21:30)}

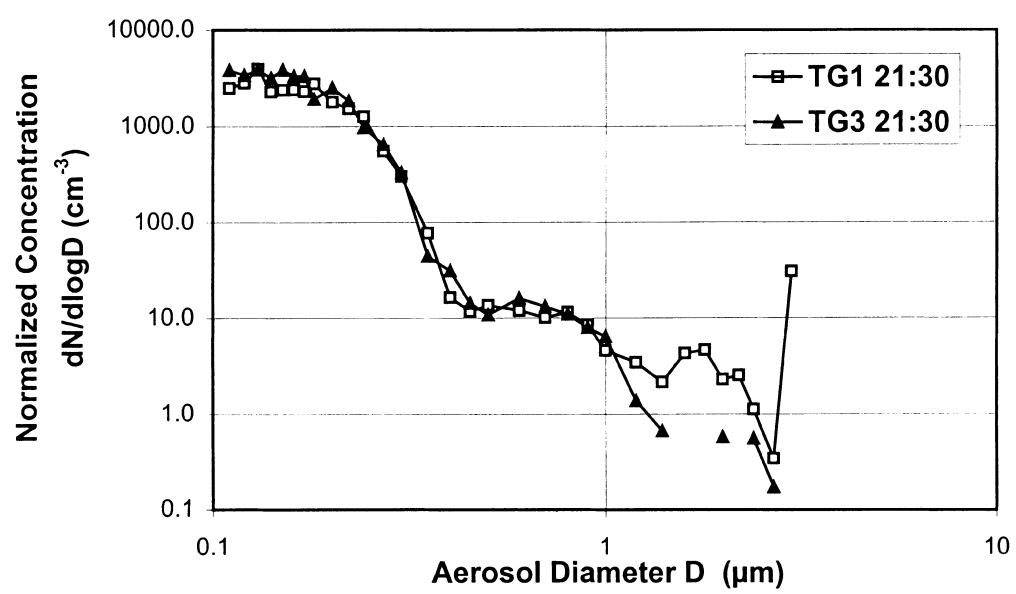

Fig. 9. Comparison of upwind and downwind accumulation mode aerosol spectra during HILLCLOUD run 2.

analyzer (H-TDMA) systems (at PDH and TG3) measured hygroscopic growth of individual aerosol particles when taken from a dry state (relative humidity, $\mathrm{RH}<5 \%$ ) to a controlled humidified state (nominally $\mathrm{RH}=90 \%$ ). For most of the time during the experiment, the aerosol particles exhibited an internal mixture from a hygroscopic point of view, in the sense that they all had similar, and rather high, growth factors. At PDH these growth factors (GFs) ranged from 1.65 to 1.76 over the size range 35 to $440 \mathrm{~nm}$ in clean marine air to slightly lower values of 1.62 to 1.73 in polluted European air masses (Swietlicki et al., 2000). Almost hydrophobic particles (GFs $<1.15$ at 90\% $\mathrm{RH}$ ) appeared during incidents of local pollution, and these particles were observed more frequently at dry particle sizes smaller than $166 \mathrm{~nm}$. Due to the relatively low wind speeds at $\mathrm{PDH}$, externally 


\section{ACE-2 Hillcloud: ASASP-X Aerosol Size Distributions TG1-TG3 comparison (Run 5 14/07/97: 07:30)}

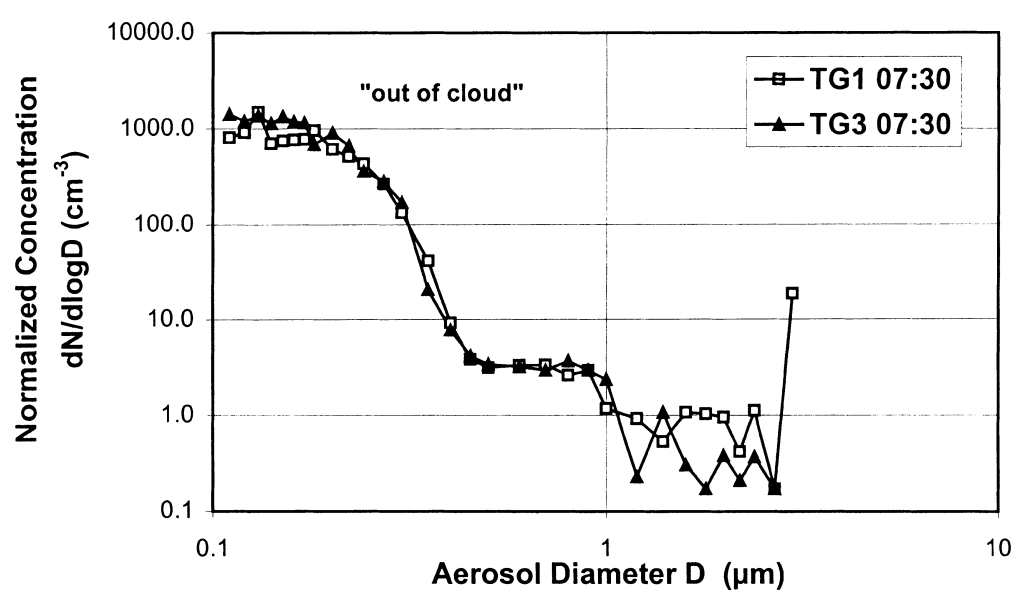

Fig. 10. Comparison of upwind and downwind accumulation mode aerosol spectra within a cloud free period during HILLCLOUD run 5.

DMPS Size Distribution Comparison - (Run 8, 22/07/97 22:00z)

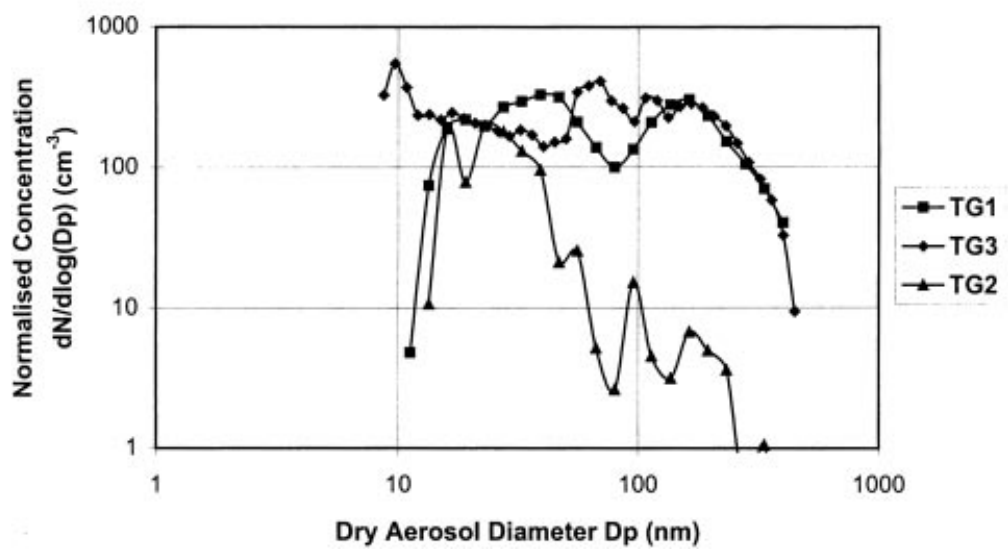

Fig. 11. Comparison of DMPS aerosol spectra measured upwind, in-cloud and downwind during HILLCLOUD run $8(22 / 07 / 97$ at $22: 00 z)$.

mixed sea salt particles with growth factors $>2.0$ were seen only on a few occasions during the experiment, while at the downwind TG3 site, sea spray particles were observed more frequently, and then mostly at the $440 \mathrm{~nm}$ particle size and towards the end of the experiment (7-22 July 1997).

Growth factor changes between PDH and TG3 of the order of about 0.05 units can be considered significant. Barely significant changes were observed only during the latter HILLCLOUD runs (6-8), and then only for particles of $73 \mathrm{~nm}$ dry size or larger. Particles activated in the hill cap cloud might have been modified during the cloud passage by dissolution and subsequent fixation of soluble gases such as $\mathrm{SO}_{2}$. This would tend to increase the soluble volume fraction of individual particles and thus cause an increase in 
their GFs. There may be several reasons for the apparent lack of growth factor increases over the hill: (i) The more-hygroscopic particles were nearly fully soluble to begin with; (ii) The concentrations of soluble precursor gases were small, e.g., $\mathrm{SO}_{2}$ concentrations were typically a few tens of pptv and the time for uptake and oxidation in-cloud was short (Flynn et al., 2000). To summarise, there were no strong indications that single cloud passages through the cap cloud had a significant effect on the hygroscopic properties of the activated aerosol particles in the marine boundary layer air masses studied. However, if the aerosol have already become substantially internally mixed following several days of processing over the ocean upwind of Tenerife then this is to be expected.

3.3.3. Aerosol chemical composition and mass. Information on the size segregated chemical composition of the aerosol both upwind and downwind of the cap cloud was obtained from measurements undertaken using low pressure 5-stage Berner impactors (BIs) and multiple stage (for collection of aerosol and gases) filter packs (FPs). The former were operated in pairs (with Tedlar foils for later chemical analysis by ion chromatography and aluminium foils for gravimetric mass analysis) during HILLCLOUD runs at both TG1 and TG3, while the latter were operated at PDH, TG1 and TG3 during and outside cloud events. The BIs were equipped with $10 \mu \mathrm{m}$ inlets to prevent collection of particles larger than $10 \mu \mathrm{m}$ ambient size, and had size cuts at 5.0, 1.6, 0.52, 0.17 and $0.01 \mu \mathrm{m}$ in successive stages (enabling collection of particles with mean aerodynamic diameters of 7.1, 2.8, 0.91, 0.30 and $0.04 \mu \mathrm{m}$ respectively). The FPs separated particles into course mode $(>2.5 \mu \mathrm{m}$ aerodynamic diameter) aerosol and fine mode $(<2.5 \mu \mathrm{m})$ aerosol. Both BIs and FPs were operated with a $3 \mathrm{~h}$ collection period. In addition to analysis for major inorganic ions $\left(\mathrm{Cl}^{-}, \mathrm{NO}_{3}^{-}\right.$, total $\mathrm{SO}_{4}^{2-}$, methyl sulphonic acid (MSA), $\mathrm{NH}_{4}^{+}$, etc.) the filter packs simultaneously collected $\mathrm{HCl}, \mathrm{HNO}_{3}, \mathrm{SO}_{2}$ and $\mathrm{NH}_{3}$, and additional species measured only at TG1 and TG3 were formic acid, acetic acid, and aerosol formate and acetate. The essential results will now be summarised.

The total mass loading of the Tenerife aerosol and of individual soluble aerosol species varied with airmass type during ACE-2, and these were considerably higher for all species during continental pollution outbreaks. The range of the FP loadings of chloride, sulphate and nitrate for the HILLCLOUD run periods are presented in Table 4. The total mass of aerosol measured by the BIs in the size range $0.01-10.0 \mu \mathrm{m}$ during the experiment varied between $10 \mu \mathrm{g} \mathrm{m}^{-3}$ and about $50 \mu \mathrm{g} \mathrm{m}^{-3}$ and peaked during the first ACE-2 pollution event of the 8-9 July.

Fine mode/coarse mode mass ratios measured by the FP at TG1 were $24.0\left(\mathrm{NH}_{4}^{+}\right), 4.26$ (non sea salt sulphate, NSSS), 1.70 (MSA), 1.27 $\left(\mathrm{SO}_{4}^{2-}\right), 0.18\left(\mathrm{NO}_{3}^{-}\right)$and $0.06\left(\mathrm{Cl}^{-}\right)$. The presence of $\mathrm{Cl}^{-}$and $\mathrm{NO}_{3}^{-}$within the larger particles resulted in losses due to deposition during transport between TG1 and TG3, which greatly exceeded those of the sulphur species, and which were increased in the presence of cloud. Of the $\mathrm{SO}_{4}^{2-}$ in the fine fraction, $97 \%$ was of non-sea salt origin, compared to $29 \%$ in the coarse $(>2.5 \mu \mathrm{m})$ fraction. Mean MSA/NSSS molar ratios (coarse mode plus fine mode) were similar at TG1 (0.049) and TG3 (0.048), but for coarse particles only ratios were much higher $(0.12$ at TG1 and 0.17 at TG3), and for fine particles only were somewhat lower ( 0.040 at TG1 and 0.039 at TG3), suggesting that MSA production was favoured relative to NSSS within larger particles, and that coarse mode MSA was produced during transport between TG1 and TG3. MSA/NSSS ratios were, on average, higher in cleaner air containing less anthropogenic NSSS, although absolute concentrations of MSA were sometimes enhanced in air masses containing a continental component, indicative of more rapid DMS oxidation. In clean air, MSA/NSSS ratios for the coarse mode aerosol greatly exceeded those for the fine mode, at both TG1 and TG3, while in polluted air ratios for both size fractions were very similar.

Particulate $\mathrm{NH}_{4}^{+}$and MSA were produced as a result of chemical reactions occurring during transport between TG1 and TG3. For the FP fine mode, similar mass equivalent ratios $\left[\mathrm{NH}_{4}^{+}\right] /$ $[\mathrm{NSSS}]+\left[\mathrm{NO}_{3}^{-}\right]+[\mathrm{MSA}]$ obtained for both sites showed that no further neutralisation had occurred during transport, in contrast to the coarse mode, for which ratios were higher, by a factor of 3 , at TG3, showing that neutralisation and production of coarse mode $\mathrm{NH}_{4}^{+}$had occurred. This process appeared to have pro- 
ceeded independently of local cloud condition. However in-cloud processes (probably oxidation of dimethylsulphoxide, DMSO) resulted in production of MSA, notably within the coarse mode, for which a mean TG3/TG1 concentration ratio of 1.46 was obtained during periods when cloud was present at TG2 (compared to a mean ratio of 0.93 under clear conditions). Total (fine plus coarse) MSA concentrations were higher at TG3 during both cloudy and clear periods, with mean concentration ratios of 1.09 and 1.05 , showing that MSA production had occurred irrespective of any particle size redistributions. The data also indicate that additional NSSS may have been produced during transport between TG1 and TG3. Although some loss of coarse mode NSSS occurred during transport, such losses were reduced under cloudy conditions, due either to growth of fine mode particles into this size range, or to in-cloud oxidation (of $\mathrm{SO}_{2}$ and/or DMS).

A comparison of aerosol measurements made at PDH (FP) and TG1 (by BI and FP) suggest the aerosol composition was similar at both upwind sites for the whole of the experiment. BI data from TG1 and TG3 (available only during periods of cloud cover at TG2) show a loss of total chloride in crossing over the hill (in agreement with FP results) while total loadings of other ions (e.g., sulphate and ammonium) remain similar upwind and downwind. This is consistent with the greater deposition of the larger aerosol (which contain the majority of the $\mathrm{Cl}^{-}$mass) over the hill. BI data have been analysed here by calculating the $\%$ contribution of each species to the total soluble mass loading in each size range measured at TG1 and TG3. This enables comparison of upwind and downwind data excluding the effects of size dependent aerosol losses (e.g., through deposition) between the two sites. Figs 12 and 13 present a comparison of the size segregated \% composition of each species at TG1 and TG3 for typical clean and polluted cases (from runs 1 and $2)$, respectively.

Generally, in both clean and polluted cases, the BI data at TG1 suggest the largest aerosols $(>1.6 \mu \mathrm{m})$ are comprised mainly of sodium and chloride (accompanied by small fractions of other sea salt ions e.g., $\mathrm{Mg}^{2+}$ ) while the smallest aerosols $(<0.15 \mu \mathrm{m})$ are comprised of a mixture of ammonium, sulphate, sodium and chloride ions, the contribution of ammonium sulphate being slightly greater in polluted cases and sodium chloride more in clean cases. Between 0.15 and $0.45 \mu \mathrm{m}$ the accumulation mode aerosol in both regimes are dominated by ammonium sulphate. Nitrate is associated mainly with the larger sea salt aerosol, and the $\%$ contribution is largest in polluted cases, and often provides a significant (but variable) contribution to the composition at the smallest sizes $(<0.15 \mu \mathrm{m})$ too (probably as a result of repartitioning upwind). In general, $\mathrm{SO}_{4}^{2-}$, MSA and $\mathrm{NH}_{4}^{+}$ions reside mainly in the particle size range below $1.6 \mu \mathrm{m}$. Comparison of BI data (corrected for internal losses) with FP data suggests at least $50 \%$ of the sea salt aerosol mass lies above the upper $10 \mu \mathrm{m}$ cut size of the BIs.

The exact effects of passage through the cap cloud system on aerosol composition often depend largely on the distribution of species across the input distribution (and hence the history of the aerosol upwind of Tenerife) as well as concentrations of soluble species (e.g., $\mathrm{NH}_{3}, \mathrm{HNO}_{3}, \mathrm{HCl}$, etc.) and sulphate precursors (e.g., $\mathrm{SO}_{2}, \mathrm{H}_{2} \mathrm{O}_{2}, \mathrm{O}_{3}$ ) in the gas phase. One result common to both clean and polluted cases is that passage through the cloud system leads to a large increase in the $\%$ contribution of nitrate to the mass of the smallest aerosol $(<0.15 \mu \mathrm{m})$, sometimes accompanied by a small gain in ammonium (particularly when the upwind aerosol loading at this size is low). At the mid-size range $(0.45-1.6 \mu \mathrm{m})$, there is usually a significant gain in ammonium and often a gain in sulphate, at the expense of the fractional contribution of sodium and chloride (often with some loss of the latter). Since the aerosol between $0.15-0.45 \mu \mathrm{m}$ are already dominated by ammonium sulphate such changes (e.g., following sulphate production) are not generally obvious in this analysis. At larger sizes $(>1.6 \mu \mathrm{m})$ fractional changes in species concentrations become less apparent (as the total mass of these aerosol is already large). However, changes in chloride loading are sometimes observed (often a loss) along with small increases in the ammonium and sulphate fractions. In this analysis, similar trends in species composition changes are observed in passing from TG1 to TG3 in both clean and polluted conditions. However, to examine fully the effect of processing requires a detailed examination of the absolute changes in species loadings occurring at each size. Small fractional changes in the composition of large aerosol can provide 
HILLCLOUD BI Aerosol Composition : TG1 (Run 2 08/07/97 07:00z)

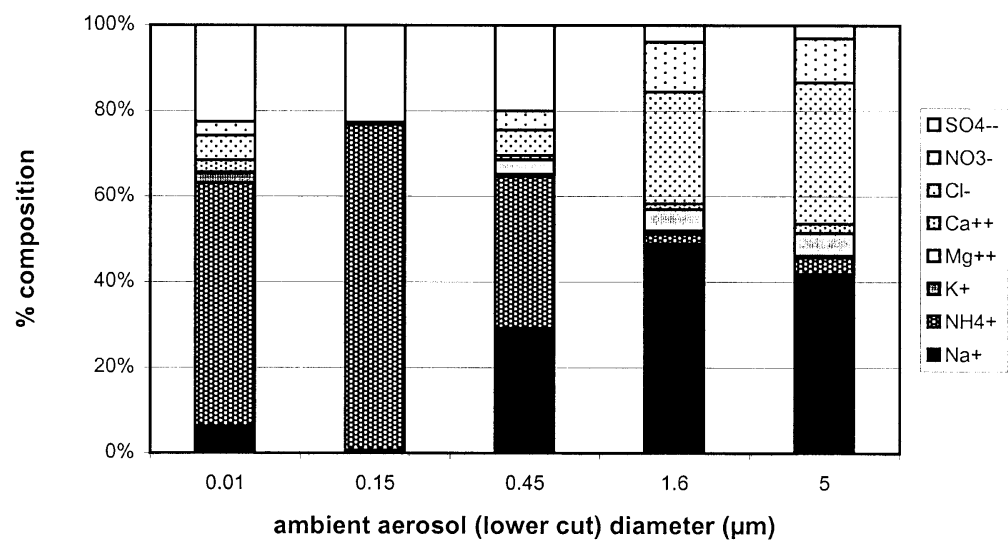

HILLCLOUD BI Aerosol Composition : TG3 (Run 2 08/07/97 06:36z)

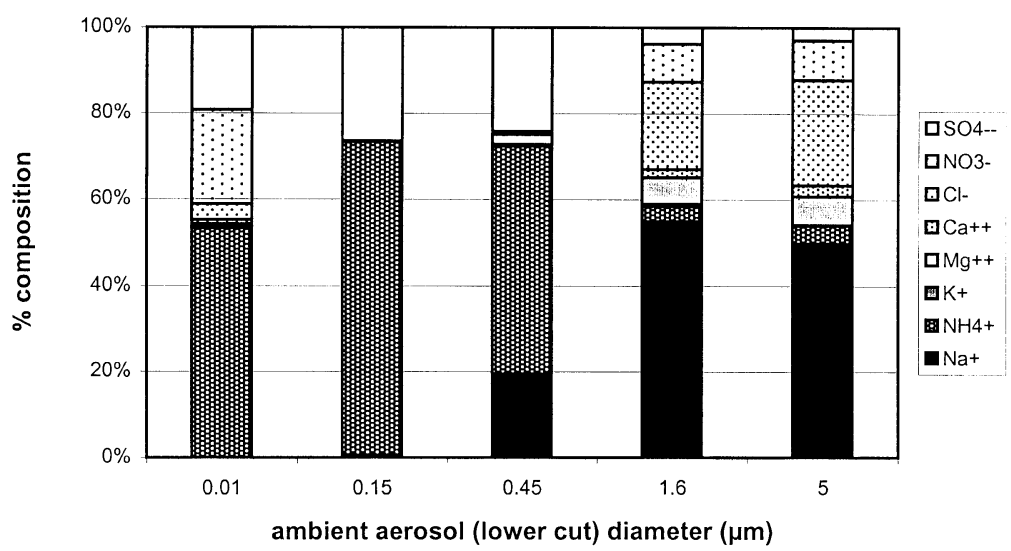

Fig. 12. Comparison of the Berner impactor size segregated composition of the major inorganic ions (expressed as a percentage of the total inorganic soluble mass loading at each size) at TG1 and TG3 during the clean marine HILLCLOUD run 1.

sufficient material (if outgassed and repartitioned) to cause significant modification of smaller aerosol, which require only a small increase in total mass to produce large changes in composition and size.

The results presented here are broadly consistent with those of Flynn et al. (2000) who use a cloud chemistry and microphysics model to examine HILLCLOUD case studies of cloud processing of aerosol. They compare predicted cloud and downwind aerosol properties with measurements made in cloud at TG2 and downwind at TG3 (using PDH and TG1 measurements of aerosol and gases as input). Flynn et al. (2000) predict significant growth of the smallest activated particles due to cloud processing during clean runs, but less significant changes during polluted periods. The modification is due mainly to the

Tellus 52B (2000), 2 
HILLCLOUD BI Aerosol Composition : TG1 (Run 1 02/07/97 02:15z)

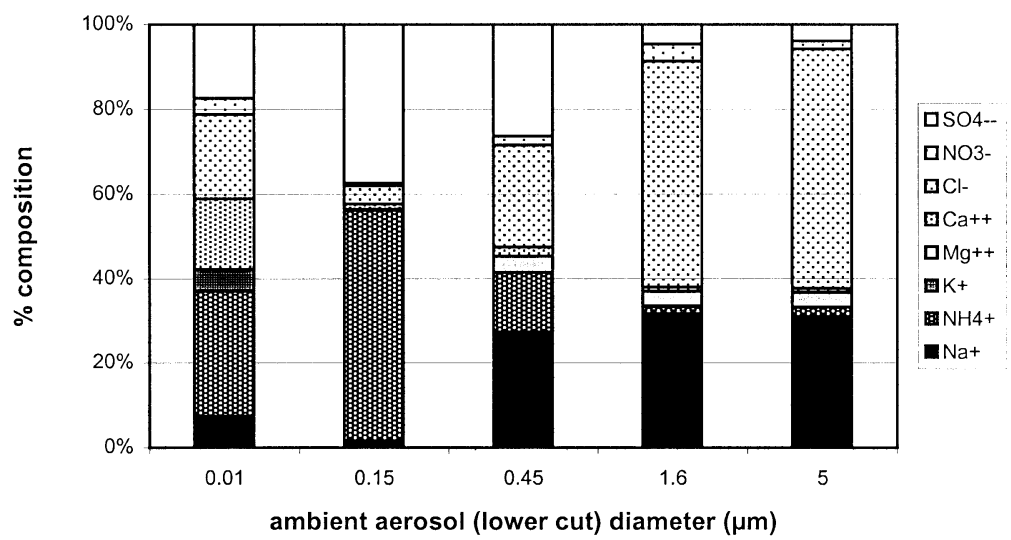

HILLCLOUD BI Aerosol Composition : TG3 (Run 1 02/07/97 02:15z)

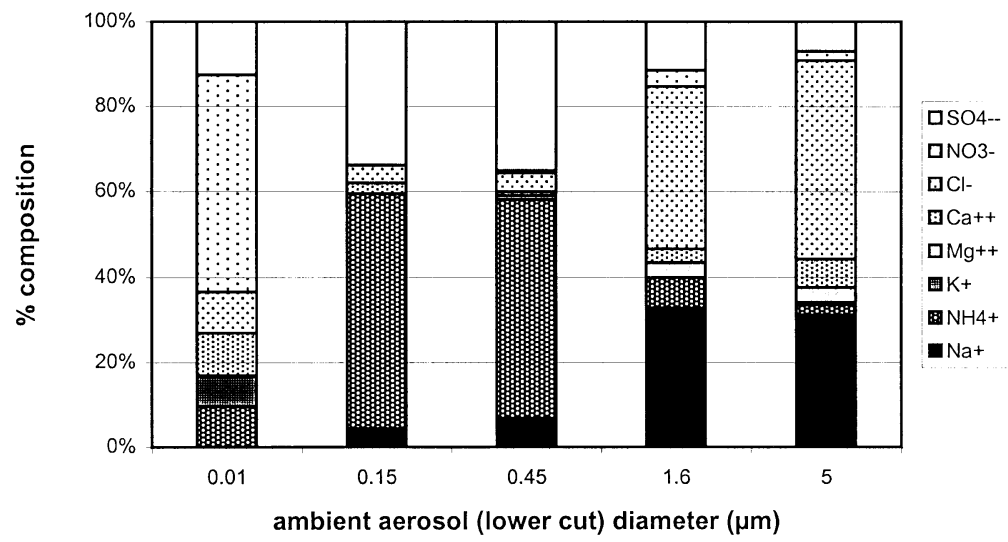

Fig. 13. Comparison of the Berner impactor size segregated composition of the major inorganic ions (expressed as a percentage of the total inorganic soluble mass loading at each size) at TG1 and TG3 during the polluted HILLCLOUD Run 2.

take-up of nitric and hydrochloric acid vapours by the smaller activated particles. This is fixed by the take-up of ammonia. The oxidation of S(IV) by the dominant oxidant hydrogen peroxide is seen to make only a small contribution (mainly because of the short transit time through cloud and the low concentrations of $\mathrm{SO}_{2}$ present in solution). Ammonia is taken up onto most sizes of particle from the gas phase. In polluted cases very little modification of the aerosol spectrum is predicted, but the very small changes that do occur in the model are due to the take up of $\mathrm{HNO}_{3}$ and $\mathrm{HCl}$ from the gas phase, and the repartitioning of these species from the nitrate and chloride rich particles (generally the larger particles) onto the smaller particles. Ammonia is also predicted to be outgassed from ammonium-rich categories at times, and so becomes available for 
uptake into, and neutralising of, the more acidic drops. The net effect of the differences between clean and polluted cases, is therefore, a greater modification of the aerosol size distribution in the former.

\subsection{Cloud properties}

3.4.1. Cloud water chemistry. A number of cloud water collectors were deployed at TG2 in order to determine the bulk and size dependent chemistry of the cloud water (Subsection 2.2 and Table 1). One active collecting system (newly developed by IEP) used a differential fog sampling system consisting of a series of two three-stage impactors. Each collector allowed size-fractionated sampling in three different size intervals and, overall, enabled the sampling of drops in five defined diameter ranges: $7-11 \mu \mathrm{m}, 11-17 \mu \mathrm{m}$, $17-22 \mu \mathrm{m}, 22-33 \mu \mathrm{m}$, and $>33 \mu \mathrm{m}$, with a sampling time resolution of generally $3 \mathrm{~h}$ (depending on the cloud LWC). $\mathrm{pH}$ and conductivity measurements, and analyses for the major ions using ion chromatography were performed shortly after collection. Samples were collected during most cloud events of sufficient duration, both for clouds formed on marine air masses (as on 26 June, 2 and 22 July) and during periods of advection of anthropogenically influenced air masses into the region (as on 7-8, 8-9 and 17-18 July).

Measurements of the size dependence of cloud droplet chemistry using a 2-stage size-fractionating Caltech active strand cloud collector (sf-CASCC) were also undertaken. Averaged across the period in which it was operated, these revealed that concentrations of all measured inorganic ions (chloride, nitrate, sulfate, sodium, potassium, ammonium, calcium and magnesium) and concentrations of trace metal catalysts ( $\mathrm{Fe}$ and $\mathrm{Mn}$ ) were usually enriched in large cloud drops $(d>23 \mu \mathrm{m})$ relative to their concentrations in smaller drops $(4<d<23 \mu \mathrm{m})$. Small drops were generally more acidic than large drops, with $\mathrm{pH}$ differences as large as two $\mathrm{pH}$ units observed.

Results from the IEP collector also highlight a very significant size dependency of droplet composition and solute concentration for all cloud episodes. The ionic strength of the droplet solutions varies greatly as a function of droplet diameter with variations of up to an order of magnitude among drops of different size.
Furthermore, the solute concentration size dependency is significantly modified depending on the air mass origins: the ionic concentration is larger in the coarse droplet range for clouds formed during advection of European air masses (the concentration of droplets $>33 \mu \mathrm{m}$ is $10 \times$ higher than that of droplets of smaller sizes) while small $(7-11 \mu \mathrm{m})$ and intermediate $(17-23 \mu \mathrm{m})$ drop size ranges are more concentrated in clouds formed on marine aerosols. The difference in droplet concentration and composition between marine (22 July) and anthropogenic (7 July) air masses is shown in Fig. 14. As in the sf-CASCC case, droplet $\mathrm{pH}$ also varies according to the droplets diameter but shows quite different behaviour between marine and anthropogenic cases (Fig. 14). Droplets formed on anthropogenic aerosols were substantially more acidic than those forming on marine aerosols, with $\mathrm{pHs}$ ranging from 3.5 to 4.5 in the first case and 4.5 to 6 in the second case. Moreover, the $\mathrm{pH}$ often changes by up to $2 \mathrm{pH}$ units over the droplet spectra. The causes for the observed solute size dependency are still under investigation, but it is clear that the presence of anthropogenic aerosols substantially modified the chemistry of clouds during HILLCLOUD.

The implications of these observations are numerous. First, it is clear that the use of size-resolved droplet collectors can significantly improve our understanding of the mechanisms leading to the observed physical and chemical properties of clouds. In fact, a bulk sample of cloud droplets gives a very biassed view of the cloud chemical properties, especially during anthropogenic cases. Second, the very large differences in $\mathrm{pH}$ and cloud water composition across the spectrum can greatly influence the reactivity within cloud droplets. Given the variations of pH seen in Fig. 14, the oxidation rate of $\mathrm{SO}_{2}$ by ozone could vary by more than one order of magnitude over the droplet spectrum. Knowledge of both the droplet spectra and the solute size dependency is therefore required for a proper assessment of anthropogenic effects on clouds in the marine atmosphere.

In general, however, predictions of aqueous sulphate production rates based on measured cloudwater compositions suggest that S(IV) oxidation by hydrogen peroxide is usually much faster than S(IV) oxidation by ozone or trace metal catalysed auto-oxidation. Although the observed chemical heterogeneity present among 

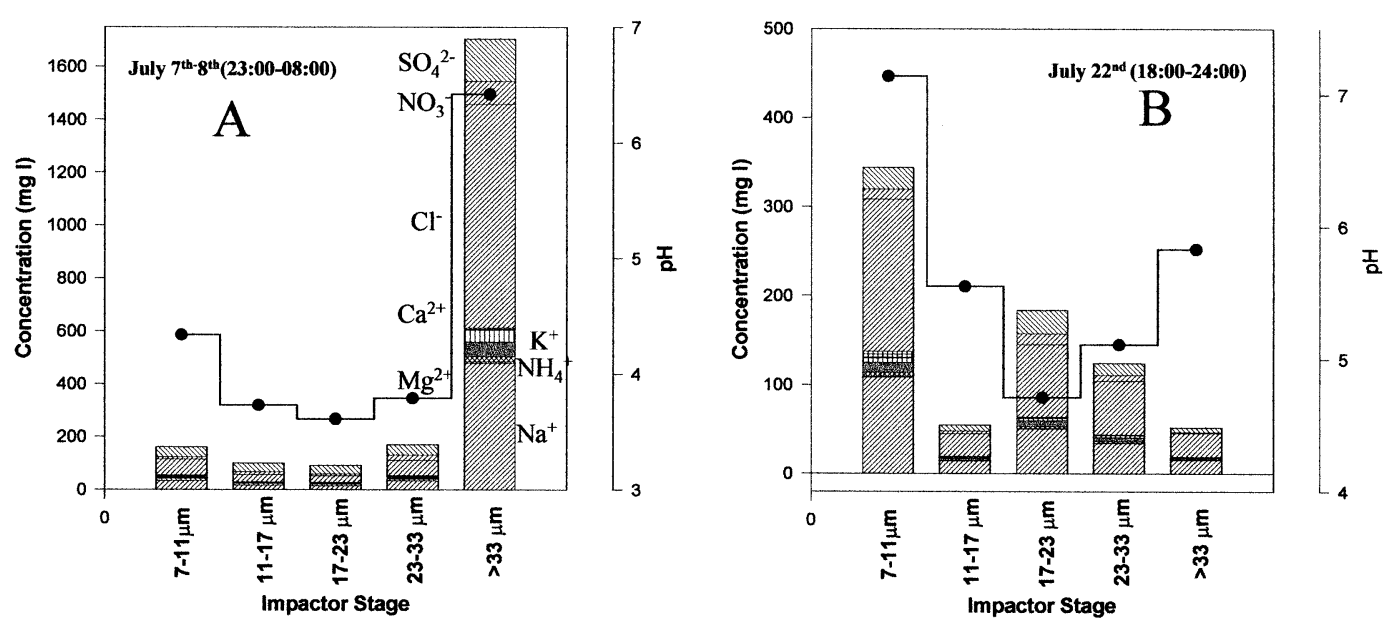

Fig. 14. Composition and concentration of species in cloud droplets in different diameter ranges for: (A) 7-8 July (polluted case, run 2) and (B) 22 July (marine case, run 8). Also shown is the $\mathrm{pH}$ in each size range.

sampled cloud drop populations is capable of significantly enhancing rates of S(IV) oxidation by the ozone (as suggested above) and metal catalysed pathways, this heterogeneity has little effect on the predicted overall rate of sulphate production due to the dominance of the hydrogen peroxide pathway. In addition, hydrogen peroxide and ammonia were found in roughly equal amounts in all droplet sizes since these species had recently been taken up from the gas phase. Concentrations of dissolved S(IV) (from online analysis of bulk sampled water from passive collectors) were generally very small, and so it is expected that the oxidation of S(IV) by hydrogen peroxide was rate limited by the take up of $\mathrm{SO}_{2}$ into aqueous solution. This has been confirmed by the modelling studies of Flynn et al. (2000)

3.4.2. Cloud microphysics. Cloud liquid water content (LWC) was continuously measured at the ridge top site $\mathrm{TG} 2$ by a Particulate Volume Monitor (PVM, Gerber Scientific Inc.). This instrument ran continuously from 17 June to 23 July (apart from 2 periods of instrument failure near the end of runs 1 and 3 , when the instrument became waterlogged). The highest recorded LWCs of around $600 \mathrm{mg} \mathrm{m}^{-3}$ were measured on 23 June, 24 June, and during run 1 on 2 July. Measured values of LWC were generally in good agreement (to better than $15 \%$ ) with adiabatic values calculated using either observed cloud base levels or cloud base heights determined from the ceiliometer installed at TG1.

Cloud droplet size distributions were measured at TG2 both by a Forward Scattering Spectrometer Probe (FSSP, a laser scattering device, made by PMS and upgraded by DMT with fast electronics to remove instrument deadtime effects during measurements) and a Droplet Aerosol Analyzer (DAA, employing an electrostatic charging/mobility technique). The latter also enabled the relationship between the cloud and interstitial aerosol droplets and their dry residue sizes to be determined (see Martinsson et al., 2000, for more details).

Table 4 summarises the very large range of droplet concentrations observed during the eight HILLCLOUD runs, varying from as low as $50 \mathrm{~cm}^{-3}$ in the very maritime (early) part of run 8 , to over $2500 \mathrm{~cm}^{-3}$ in the heavily continentally influenced run 2. In general there was good agreement between the FSSP and DAA derived droplet concentrations after correction of the former for coincidence errors. However, during the polluted runs 2 and 3, the number of aerosol activated into cloud droplets observed by the DAA was so large that the problem with coincidence in the FSSP could not be overcome by the normal corrections. This caused the FSSP to saturate out and to see many fewer droplets than the DAA in these runs. The droplet numbers observed by the DAA in 
runs 2 and 3 were much higher than have previously been detected in this type of cloud.

Droplet numbers were also inferred by comparing upwind and interstitial DMPS spectra (e.g., as in Fig. 11) to determine the loss of aerosol through activation between the sites. Excellent agreement between the droplet number concentrations measured directly and inferred by this method was always obtained (Flynn et al., 2000; Martinsson et al., 2000). In addition, the DAA interstitial residue spectra showed close agreement with the TG2 DMPS spectra, and when recombined with the DAA cloud droplet residue spectra reproduced well the aerosol spectra measured upwind by the DMPSs (Martinsson et al., 2000).

Fig. 15 shows the relationship between DAA cloud droplet number concentration $N$, and TG1 DMPS aerosol number for the whole HILLCLOUD project. It can be seen that droplet numbers vary almost linearly with aerosol number (over a wide range of $N$ ). However, the FSSP droplet numbers begin to fall away above $1200 \mathrm{~cm}^{-3}$ (but vary linearly with the number of aerosol larger than $0.1 \mu \mathrm{m}$ - possibly indicating the activation of droplets on small aerosol which grow to too small a size for detection by the FSSP). It had previously been assumed (based mainly on data from laser scattering devices without fast electronics) that the cloud droplet number concentration saturated, reaching a plateau (at concentrations of a few hundred per $\mathrm{cm}^{3}$ ) as the aerosol number concentration increased. These new results may, therefore, have important implications for the parameterisation of droplet numbers in relation to aerosol numbers in marine clouds (especially for those forming within aged continental airmasses), if the Tenerife cap cloud is representative of the majority of clouds in the MBL in this area. Such parameterisations are generally used in large scale and global climate models.

The DAA data show a sharp transition in the scavenging ratio of aerosols activating to form cloud drops as a function of dry aerosol size (Martinsson et al., 2000) during HILLCLOUD. This implies that a single peak supersaturation and a simple and abrupt activation process occurred in the updraughts near to cloud base. Generally, this supersaturation was higher in clean conditions and lower in the polluted episodes. The average peak cloud supersaturation however, was seen to be around $0.2 \%$.

The vertical velocities encountered during HILLCLOUD close to cloud base were mostly in the range of 0.5 to $1.5 \mathrm{~m} \mathrm{~s}^{-1}$ (Flynn et al., 2000). These updraughts are similar to those often encountered in stratocumulus and small cumulus clouds. However, the highest droplet number concentrations of $2800 \mathrm{~cm}^{-3}$ were observed during run 2 , in conditions of shallow cloud and strong winds. The cloud base vertical velocity reached $1.8 \mathrm{~m} \mathrm{~s}^{-1}$ during this period. In a sensitivity study, Flynn et al.

DAA Drop Number versus DMPS Aerosol Number (all HILLCLOUD Events)

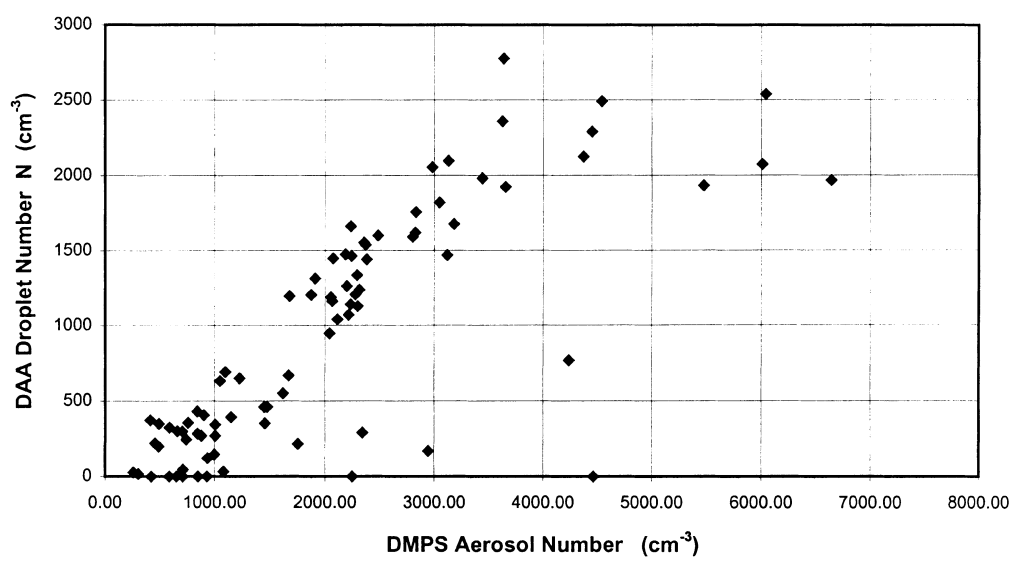

Fig. 15. Scatter plot of DAA droplet number verses TG1 DMPS aerosol number for the ACE-2 HILLCLOUD experiment.

Tellus 52B (2000), 2 
used the observations of cloud droplet number, aerosol number and aerosol hygroscopic properties to predict the droplet number concentrations which would be expected in a stratocumulus cloud with a lower maximum vertical velocity of $0.3 \mathrm{~m} \mathrm{~s}^{-1}$ at cloud base. The results obtained suggest that such clouds would still activate up to 1000 droplets $\mathrm{cm}^{-3}$ in the most polluted events, significantly higher than would be expected from the relationships currently used in global climate models (e.g., Jones and Slingo, 1996). These high aerosol loadings and droplet number concentrations are thus to be expected when polluted continental plumes are advected over the ocean and when there is little aerosol loss from wet deposition processes. The strongly linear relationship observed between the droplet number concentration and the number of accumulation mode aerosol will, therefore, have important implications for the parameterisation of clouds in global climate models representing the indirect effect of the atmospheric aerosol.

\section{Conclusions}

Measurements were made over an extensive period during the ACE-2 HILLCLOUD experiment (from 21 June to 23 July 1997). 8 intensive periods of measurements were undertaken during cloud events mainly at night.

A wide range of airmass conditions were sampled during these periods, from clean maritime events to outbreaks of polluted continental air from Europe.

During polluted outbreaks, aerosol number concentrations were much higher than the background maritime values. The very high aerosol numbers tended to be dominated by ammonium sulphate particles in the accumulation mode. The vast majority of these particles were very hygroscopic, and had growth factors similar to those of ammonium sulphate or ammonium hydrogen sulphate. The polluted events were further characterised by enhanced ozone concentrations, but $\mathrm{NO}_{x}$ had almost completely disappeared away from local (daytime) anthropogenic sources.

In cloud, a very wide range of droplet number concentrations were observed in the different conditions. These droplet numbers were seen to be nearly linearly related to aerosol number over the full range of concentrations. In the most polluted cases, the highest droplet number concentrations reached were in excess of $2500 \mathrm{~cm}^{-3}$. Measurements showed that activation was occurring at a single level near to cloud base where vertical velocities were typically in the range $0.5-1.5 \mathrm{~m} \mathrm{~s}^{-1}$ (similar to those encountered in stratocumulus clouds in the area). In these conditions, the droplet aerosol analyzer (DAA) detected more cloud droplets than the corrected FSSP with fast electronics. Such high droplet numbers could not therefore be measured by standard aircraft borne FSSPs. This result suggests that very high droplet numbers may be expected in clouds formed in well aged pollution plumes, where little wet deposition has occurred. Under these circumstances the large number of aerosol particles produced by anthropogenic activity will have had sufficient time to become internally mixed and hygroscopic. In a simulation of droplet activation in clouds with updraughts of only $0.3 \mathrm{~m} \mathrm{~s}^{-1}$ Flynn et al. (2000) still predict droplet numbers in excess of $1000 \mathrm{~cm}^{-1}$. This will have important implications for regional and global indirect radiative forcing as these clouds will have a very high albedo. This contradicts the relationship between aerosol and droplet number generally used in GCMs, which have maximum droplet concentrations of around $600 \mathrm{~cm}^{-3}$.

$\mathrm{NO}_{2}$ was present in concentrations of typically 15 to $100 \mathrm{pptv}$ and was only weakly correlated with the airmass origin, possibly suggesting that this $\mathrm{NO}_{2}$ was of marine origin. The nitrate radical, $\mathrm{NO}_{3}$, was observed at night throughout the experiment, and its main sink was identified as being its reaction with DMS to produce nitric acid.

$\mathrm{SO}_{2}$ (from local natural sources), $\mathrm{HNO}_{3}$ and $\mathrm{HCl}$ were always present. Calculations suggested $\mathrm{HNO}_{3}$ concentrations exceeded those which could be accounted for by $\mathrm{NO}_{2}$ oxidation and were higher in polluted episodes. The nitric and hydrochloric acids were thus presumed to be present as a result of outgassing from aerosol, the $\mathrm{HNO}_{3}$ from nitrate rich aerosol long-range transported from regions of combustion and $\mathrm{HCl}$ from sea salt aerosol newly formed at the sea surface.

Background ammonia gas concentrations were around 0.3 ppbv even in air originating away from the island over the sea. The take-up of ammonia by the activated droplets was important for the growth of the small aerosol. This ammonia over 
the sea, if generally present will be very important in the nucleation and growth of aerosol.

Occasions of significant aerosol growth following cloud processing were observed. This was due predominantly to the take up of nitric acid and hydrochloric acid by the smallest activated aerosol particles, which were then neutralised by the available ammonia. Although the oxidants hydrogen peroxide and ozone were abundant, the short transit time of air through the cap cloud system prevented in-cloud sulphate production from making a significant contribution to the modification of the aerosol. However, in MBL stratocumulus clouds, the extended period spent within the processor will enable conversion of the available $\mathrm{SO}_{2}$ to sulphate to occur, and hence to contribute to the modification of the aerosol. Repartitioning of nitrate, chloride and ammonium between aerosols of different initial composition in or near cloud is also expected to contribute to this modification. These effects will be very important for the growth of the small particles in the aerosol spectrum over the sea in a polluted plume. It will facilitate the growth of the small aerosol into sizes where they can act as CCN and scatter solar radiation both directly and indirectly after activation to cloud drops.

\section{Acknowledgements.}

This research is a contribution to the International Global Atmospheric Chemistry (IGAC) Core Project of the International Geosphere-Biosphere Programme (IGBP) and is part of the IGAC Aerosol Characterization Experiments (ACE) series. It has been supported by the European Commission under contract number ENV4 CT95 0058 (-PL950583) entitled: "Use of a Hill Cap Cloud to Study Cloud-Aerosol
Interactions in ACE-2" (short title: "HILLCLOUD") under the Programme Environment and Climate 1994-1998 - Topic 1212. The UK groups: UMIST, ITE, UEA and LANC (see Table 2) also acknowledge support from the UK Natural Environment Research Council (NERC) through their 5 year community research program ACSOE (Atmospheric Chemistry Studies in the Oceanic Environment), and acknowledge the BADC (British Atmospheric Data Centre) for help in organising and archiving ACSOE data. CSU's participation in ACE-2 was funded by the U.S. National Science Foundation (ATM-9509596).

The authors would also like to thank Carmen Rus Jimenez and Jose Luis Sanchez Megia of INM Centro Meteorologico Territorial de Canarias Occidental in Santa Cruz, and in particular Maria Helena Gonzalez-Jorge and Beatriz Mederos-Diaz for their invaluable assistance during the organisation and execution of the ACE-2 HILLCLOUD experiment. Finally, thanks go to Antonio Exposito Delgado, Milagro Cabrera Izquierdo and Carmen Morales Delgado, whose properties at Taganana, El Bailadero and Paiba were used as laboratories and measurement sites during HILLCLOUD. Thanks also go to the following: The FREETROPE team at PDH (Rita van Digenen and colleagues) who launched the balloon borne sondes often in the middle of the night and at short notice, the University of Miami for allowing the use of their ceiliometer at TG1, The University of La Laguna, Tenerife, for the use of facilities including laboratories in the Department of Chemistry, and also to the numerous individuals from participating institutes who contributed much time, knowledge and expertise prior to, during and following the HILLCLOUD Experiment.

\section{REFERENCES}

Allan, B. J., Carslaw, N., Coe, H., Burgess, R. A. and Plane, J. M. C. 1999. Observations of the nitrate radical in the marine boundary layer. J. Atmos. Chem. 33, 129-154.

Bower, K. N., Choularton, T. W., Gallagher, M. W., Colvile, R. N., Beswick, K. M. Inglis, D. W. F., Bradbury, C., Martinsson, B. G., Swietlicki, E., Berg, O. H. Cederfelt, S-I., Frank, G., Zhou, J., Cape, J. N., Sutton, M. A., Hargreaves, K. J., Birmili, W., Yuskiewicz, B. A., Wiedensohler, A., Stratman, F., Berner, A., Ctyroky,
P., Galambos, Z., Mesfin, S. H., Dusek, U., Dore, C. J., Lee, D. S., Pepler, S. A., Bizjak, M. and Divjak, B. 1999. The Great Dun Fell experiment 1995: an overview. Atmospheric Research 50, 151-184.

Choularton, T. W., Colvile, R. N., Bower, K. N., Gallagher, M. W., Wells, M., Beswick, M. W., Arends, B. G., Mols, J. J., Kos, G. P. A., Fuzzi, S., Lind, J. A., Orsi, G., Facchini, M. C., Laj, P., Gieray, R., Wieser, P., Engelhardt, T., Berner, A., Kruisz, C., Moller, D., Acker, A., Wieprecht, W., Luttke, J., Levsen, K., Bizjak, 
M., Hansson, H-C., Cederfelt, S-I., Frank, G., Mentes, D., Martinsson, B., Orsini, D., Svenningsson, B., Swietlicki, E., Wiedensohler, A., Noone, K. J., Pahl, S., Winkler, P., Seyffer. E., Helas, G., Jaeschke, W., Georgii, H. W., Wobrock, W., Preiss, M., Maser, R., Schell, D., Dollard, G., Jones, B., Davies, T., Sedlak, D. L., David, M. M., Wendisch, M., Cape, J. N., Hargreaves, K. J., Sutton, M. A., Storeton-West, R. L., Fowler, D., Hallberg, A., Harrison, R. M. and Peak, J. D. 1997. The Great Dun Fell cloud experiment 1993: an overview. Atmospheric environment. Special issue on the great Dun Fell cloud experiment 1993, Eurotrac subproject ground based cloud experiment (GCE) 31, 2393-2405.

Flynn, M, J., Bower, K. N., Choularton, T. W., Wobrock, W., Mäkelä, J. M., Martinsson, B., Frank, G., Hansson, H-C., Karlsson, H. And Laj, P. 2000. Modelling cloud processing of aerosol during the ACE-2 HILLCLOUD experiment. Tellus 52B, 779-800.

Johnson, D. W., Osbourne, S., Wood, R., Surhe, K., Johnson, R., Businger, S., Quinn, P. K., Wiedensohler, A., Durkee, P. A., Russell, L. M., Andrae, M. O., O’Dowd, C., Noone, K., Bandy, B., Rudolph, J. and Rapsomanikis, S. 2000. An overview of the Lagrangian experiments undertaken during the North Atlantic regional aerosol characterisation experiment (ACE-2). Tellus 52B, 290-320.

Jones, A. and Slingo, A. 1996. Predicting cloud droplet effective radius and indirect sulphate aerosol forcing using a general circulation model. Q. J. R. Meteorol. Soc. 122, 1573-1595.

Martinsson, B. G., Frank, G., Cederfelt, S-I., Berg, O. H Mentes, B., Papaspiropoulos, G., Swietlicki, E., Zhou, J., Flynn, M., Bower, K. N., Choularton, T. W.,
Makela, J., Virkkula, A. and Van Dingenen, R. 2000. Validation of very high cloud droplet number concentrations in air masses transported thousands of kilometres over the ocean. Tellus 52B, 801-814.

Milford, C., Sutton, M. A., Allen, A. G., Karlsson, A., Rosman, K., Davidson, B., Harrison, R. M. and Cape, J. N. 2000. Marine and land-based influences on atmospheric ammonia and ammonium over Tenerife. Tellus 52B, 273-289.

Nielsen, M. 1998. Meteorological observations in support of a hill cap cloud experiment. Internal report. Dept. Meteorology and Wind Energy, RISØ National Laboratory (available upon request from the Information Service Department). ISBN 87-550-2364-9.

Paluch, I. R. 1979. The entrainment mechanism of Colorado cumuli. J. Atmos. Sci. 36, 2467-2478.

Plane. J. M. C. and Nien. C. F. 1992. A differential optical-absorption spectrometer for measuring atmospheric trace gases. Review of Scientific Instruments 63, 1867-1876.

Raes, F., Bates, T., McGovern, F. and Van Liedekerke, M. 2000. The second aerosol characterization experiment (ACE-2): general context and main results. Tellus 52B, 111-126.

Swietlicki, E., Zhou, J., Covert, D. S., Hämeri, K., Busch, B., Väkevä, M., Dusek, U., Berg, O. H., Wiedensohler, A., Aalto, P., Mäkelä, J., Martinsson, B. G., Papaspiropoulos, G., Mentes, B., Frank, G. and Stratmann, F. 2000. Hygroscopic properties of aerosol particles in the Northeast Atlantic during ACE-2. Tellus 52B, 201-227.

Verver, G., Raes, F., Vogelezang, D. and Johnson, D. 2000. The second Aerosol Characterization Experiment (ACE-2): meteorological and chemical context. Tellus 52B, 126-140. 